\title{
The specialized thoracic skeletomuscular system of the myrmecophile Claviger testaceus (Pselaphinae, Staphylinidae, Coleoptera)
}

\author{
Xiao-Zhu Luo $^{1}$ (D) $\cdot$ Paweł Jałoszyński ${ }^{2} \cdot$ Alexander Stoessel $^{1,3} \cdot$ Rolf Georg Beutel $^{1}$
}

Received: 17 July 2020 / Accepted: 15 January 2021 / Published online: 2 February 2021

(C) The Author(s) 2021

\begin{abstract}
External and internal structures of the thorax of the myrmecophile beetle Claviger testaceus (Clavigeritae, Pselaphinae) were examined and documented with state-of-the-art visualization techniques. Following a general trend in the omaliine lineage (Staphylinidae), the skeletal elements of the pro- and pterothorax in Claviger reach a maximum degree of compactness, with largely reduced inter- and intrasegmental sutures and skeletal elements linked with the flight apparatus. The musculature, especially metathoracic direct and indirect flight muscles, also shows a high degree of reduction. Two forms of wings were found among individuals of $C$. testaceus, both non-functional and representing an advanced stage of reduction. However, that wing vestiges are still present and the metanotum, only slightly reduced, suggests that loss of flight in this species is likely the result of a young evolutionary process. Several structures are linked with myrmecophilous habits: small body size facilitates transportation of beetles by ant workers and makes it easier to move inside nest tunnels; the remarkably compact body and mechanically robust appendages make the beetles less vulnerable to attacks by ant mandibles; the improved elytral interlocking mechanism and unusually expanded epipleura enhance the protection of vulnerable dorsal parts of the pterothorax and anterior abdomen; and glands associated with trichomes on the posterolateral elytral angle produce secretions attractive for ants. Various modifications of the thorax and anterior abdomen lead to an optimization of intimate associations with ants. The morphological syndrome enabling these beetles to cope with life in ant colonies evolved in several steps. This is suggested by an increasing solidification of the thoracic skeleton in related non-myrmecophilous groups and also by less modified related clavigerites;for instance, ant-associated tropical species are still able to fly.
\end{abstract}

Keywords Beetle $\cdot$ Thorax $\cdot$ Myrmecophile $\cdot$ Ant-associated $\cdot 3 \mathrm{D}$

\section{Introduction}

With a world-wide distribution and more than 10,000 described species (Yin et al. 2019), Pselaphinae ranks as the second largest subfamily of the megadiverse polyphagan

Xiao-Zhu Luo

xiaozhu.luo@uni-jena.de

1 Institut für Zoologie und Evolutionsforschung,

Friedrich-Schiller-Universität Jena, Erbertstrasse 1, 07743 Jena, Germany

2 Museum of Natural History, University of Wrocław, Sienkiewicza 21, 50-335 Wrocław, Poland

3 Max Planck Institute for the Science of Human History, Department of Archaeogenetics, Kahlaische Strasse 10, 07745 Jena, Germany
Staphylinidae (over 64,000 described species, Fikáček et al. 2020). One of the most successful myrmecophilous radiations in Coleoptera took place in this subfamily, with far-reaching morphological modifications (Thayer 2016; Parker 2016a). Extreme morphological specializations, apparently linked with a far-reaching social integration in ant colonies, evolved in Clavigeritae, one of the six pselaphine supertribes with more than 300 described species (Parker and Grimaldi 2014). Bizarre morphological modifications in this clade have attracted attention of different researchers (e.g., Parker and Grimaldi 2014). However, most studies were focused on structural features of the head and abdomen, such as the distinctly reduced mouthparts and specialized armatures of abdominal and elytral trichomes (see Hermann 1982; Parker 2016a; Jałoszyński et al. 2020), and also on appeasement glands (e.g., Cammaerts 1973, 1974). The trichomes on the abdominal tergites are a presumptive synapomorphy of the 
group and linked with the association with host ants, which have been recorded to lick on these hair-like structures of several species of Clavigeritae (Hermann 1982; Cammaerts 1992, 1995, 1996).

Like other species of the genus (Parker 2016a), Claviger testaceus Preyssler, 1790 displays very advanced morphological specializations, among them the complete loss of eyes and optic neuropils (Jałoszyński et al. 2020) and the reduced and non-functional flight apparatus. Behavioral patterns of C. testaceus have been described by Donisthorpe (1927) and Cammaerts (1977) and were summarized by Hermann (1982). The regurgitation behavior of this species in interaction with workers of the host Lasius flavus (Fabricius, 1782) has been documented by Cammaerts (1992, 1995, 1996). However, the morphological information about the thorax of $C$. testaceus is still very limited, especially regarding the internal elements of the skeletomuscular system.

In the last two decades, micro-computed tomography ( $\mu$ CT) and computer-based 3D reconstruction have been demonstrated as excellent tools for exploring internal structures of beetles and other insects (e.g., Friedrich et al. 2009; Liu et al. 2018; Luo et al. 2018, 2019; Yavorskaya et al. 2019). The cephalic morphology including muscles of selected groups of the highly diversified Staphylinidae was documented in detail in a series of studies by Weide and Betz (2009) and Weide et al. (2010, 2014). In contrast, only very limited information is available on the thoracic anatomy of the family (e.g. Larsén 1966). Detailed studies on the skeletomuscular system of the thorax of Pselaphinae were completely lacking so far. We used various modern techniques to investigate and document thoracic structures of $C$. testaceus and compared the observed features with patterns found previously in less specialized beetles, for instance, Archostemata (Baehr 1975; Friedrich et al. 2009), hydrophiloid beetles capable of flight (Beutel \& Komarek 2004), or less specialized species of the staphylinoid families Silphidae and Staphylinidae (Larsén 1966). We also compare thoracic structures of $C$. testaceus with reductional patterns found in adephagan and staphylinoid species showing cryptic, subterranean life habits (Luo et al., 2018, 2019). The highly modified thoracic anatomy is then interpreted in the context of the specific myrmecophilous life style of Clavigeritae.

\section{Materials and methods}

\section{Studied species}

Specimens of Claviger testaceus were collected by P. Jałoszyński in Klasztorna Góra ad Prudnik, Poland (08.05.2019). All individuals used in this study were preserved in FAE (formaldehyde-acetic acid-ethanol). For comparative purposes, exoskeletal structures of the thorax were also studied in six free-living, predatory pselaphine species: Euplectus karstenii (Reichenbach, 1816) (Euplectitae: Euplectini), Trichonyx sulcicollis (Reichenbach, 1816) (Euplectitae: Trichonychini), Brachygluta fossulata (Reichenbach, 1816) (Goniaceritae: Brachyglutini), Bryaxis bulbifer (Reichenbach, 1816) (Goniaceritae: Bythinini), Batrisodes venustus (Reichenbach, 1816) (Batrisitae: Batrisini), and Pselaphus heisei Herbst, 1792 (Pselaphitae: Pselaphini). Specimens of these species were collected in various regions of Poland by P. Jałoszyński and preserved drymounted.

\section{Light microscopy}

Dissected body parts were cleared briefly in $10 \%$ aqueous solution of sodium hydroxide, dehydrated in isopropanol and mounted in Canada balsam, except for entire separated wings, which were studied and photographed as temporary mounts in water. Photographs were taken with a Nikon D7500 camera mounted on an Eclipse $N i$ compound microscope; image stacks were processed using Helicon Focus v. 6.8.0 (HeliconSoft Ltd.).

\section{Micro-computed tomography $(\mu \mathrm{CT})$}

Specimens were transferred from FAE to an ascending series of ethanol (70\%-80\%-90\%-95\%-100\%), stained in iodine solution, transferred to acetone, and then dried at the critical point (Emitech K850, Quorum Technologies Ltd., Ashford, UK). One dried specimen was scanned at the MPI for the Science of Human History (Jena, Germany) with a SkyScan 2211 X-ray nanotomograph (Bruker, Knotich, Belgium) with an image spatial resolution of $0.68 \mu \mathrm{m}$ (isotropic voxel size) using the following parameters: $70 \mathrm{kV}, 300 \mu \mathrm{A}, 3600 \mathrm{~ms}$ exposure time, $0.15^{\circ}$ rotation steps, frame averaging on (3), and using no filter. Projections were reconstructed by NRecon (Bruker, Knotich, Belgium) into JPG files. The $\mu$ CT-scan is stored in the collection of the Phyletisches Museum Jena. Amira 6.1.1 (Thermo Fisher Scientific, Waltham, USA) and VG studio Max 2.0.5 (Volume Graphics, Heidelberg, Germany) were used for the three-dimensional reconstruction and volume rendering.

\section{Scanning electron microscopy (SEM)}

The protocol recommended by Schneeberg et al. (2017) was modified to clean the beetles: the specimens were transferred from FAE into $70 \%$ ethanol, followed by $0.5 \%$ Triton X100 $(14 \mathrm{~h}), 5 \% \mathrm{KOH}(14 \mathrm{~h})$, glacial acetic acid $(3 \times 15 \mathrm{~min})$, distilled water (multiple times until the specimens appeared clean), and finally $70 \%$ ethanol. Subsequently, they were dehydrated and dried in an Emitech K850 at the critical point. Prior to scanning electron microscopy (SEM), samples were 
attached to a rotatable specimen holder (Pohl 2010) or small sample holders and then sputter-coated with gold (Emitech K500; Quorum Technologies Ltd., Ashford, UK). SEM observation and imaging were performed with an FEI (Philips) $\mathrm{XL} 30 \mathrm{ESEM}$ at $10 \mathrm{kV}$. Final figure plates were assembled and arranged with Adobe Photoshop CC and Illustrator CS6 (Adobe Inc., California, USA).

\section{Terminology}

Thoracic muscles were designated following Larsén (1966), but the muscular terms introduced by Friedrich and Beutel (2008) (see also Beutel et al. [2014]) were added. Different nomenclatures for thoracic muscles were compared and aligned by Friedrich et al. (2009).

\section{Results}

Two wing variants were found among studied specimens, both vestigial and non-functional, but differing in the degree of reduction: a longer and transversely folded variant I and a shorter variant II. Descriptions of exoskeletal structures are based on a specimen with wing variant I, with differences in relation to variant II indicated. Internal structures are also illustrated and described based on a specimen with variant I.

\section{Prothorax}

\section{Skeleton}

The subglobose prothorax forms a compact and strongly sclerotized capsule without visible pronoto-hypomeral edge and hypomeral-prosternal boundary. The pronotum (n1, Figs. 1a, c, 2a, 3a-b) is densely covered with apically bifurcated setae (approx. $40 \mu \mathrm{m}$ long), most of them with a more or less straight posterior orientation, except a few on the posteriormost area, which point posteromesad; the pronotum is slightly longer along the median line than the maximum width in its middle region; an indistinct narrow bead is present anterolaterally; the posterior side is moderately inflected ventrad; a pair of shallow lateral depressions on the posterior third results in a constriction of the pronotum; the lateral pronotal margins are arcuate anterior to the constriction and moderately widening posterior to it; lateral carinae and transverse basal impressions are absent; the largely smooth outer region of the hypomeron (ohy, Figs. 1c, $2 \mathrm{~b}, \mathrm{~d}, 3 \mathrm{c}-\mathrm{d}$ ) is slightly convex; it is sparsely covered with minute single-tipped setae on the anterior area and longer setae on the posterior region. The inner region of the hypomeron (ihy, Figs. $2 b, d$ ) is fused with the prosternum, and notosternal sutures are lacking. Anteriorly, the prosternum (pst, Figs. 2b, d, 3c) bears a distinct smooth collar, which is gradually narrowing laterally; the slightly raised middle region of the prosternum displays a reticulate surface pattern; anteriorly it connects with the collar, and posterolaterally it forms a distinct and broad bead enclosing the coxal cavities; dorsolaterally it reaches the posterior pronotal area; short setae are sparsely distributed on the surface. No foveae are present on the prosternum. A pronotosternal joint and procoxal fissures are absent. The postcoxal process (pcp, Fig. 2b) is reduced. A mesospiracular peritreme is not developed. The procoxal cavities (cc1, Figs. 2b, 3c) are separated by a short prosternal carina (psc, Fig. 3f) in the midline, and the procoxal sockets are open posteriorly.

The thin and plate-like profurcal arms (fuc1, Fig. 2d, 3e-f) are vertically emerging from the posterior prosternal margin and basally separated. The protrochantin (fused with cryptopleuron internally) is not exposed and not recognizable as an individual structure. The slightly curved and plate-like cryptopleuron is anterolaterally located within the prothorax; dorsally it reaches only the mid-height of the segment.

The subconical procoxae (cx1, Figs. 1c, 3c) are close to each other medially, with a large concealed lateral extension (ce, Fig. 5d) reaching far into the prothoracic capsule; the proximal area is smooth and the distal part reticulate; a round lateral depression fits with the femur in its elevated position; a lateral keel is missing. The trochanter (tr1, Figs. 1c, 4a) appears bipartite, divided into two regions by a distinct constriction: (1) a glabrous subglobular basal part and (2) a distinctly elongate distal part with several short setae on its reticulate surface. The dorsal and ventral edges of the subparallel femur (fem1, Figs. $1 \mathrm{~b}, 4 \mathrm{a})$ are very slightly curved; its proximal edge articulating with the trochanter is oblique and its distal edge nearly straight, only very slightly rounded; about a proximal third of the femoral surface is reticulate and the remaining distal area smooth; the entire surface bears a regular but sparse vestiture of setae; a distinct distoventral furrow fits with the tibia in its flexed position. The tibia (tib1, Figs. 1b, 4a) is as long as the femur but narrower; it is narrowed and curved proximally, indistinctly narrowed distally, and moderately widened in its middle region; the surface is sparsely setose and lacks robust spines. The tarsus (tar1, Figs. 4a, d) is three-segmented, with the proximal tarsomere (tm1, Fig. 4d) largely hidden below the apical portion of the tibia; the distal tarsomere (tm3, Fig. 4d) is about eight times longer than the middle segment; the tarsomeres bear several long setae, and several additional minute setae are inserted on the distal part of tarsomere 3, which also bears a shallow U-shaped notch distally for the tarsal claw in its abducted position. The single claw (tcl1, Fig. 4d) is short and stout, with a rounded apex. The forelegs excluding the coxa are approximately 1.34-mm long; the ratio of trochanter/femur/ tibia/tarsus is $1.67 / 3.4 / 3.4 / 1$.

\section{Musculature (Fig. 5)}

M1 (M. pronoti primus) [Idlm2], O (= origin): posteromedian pronotal area, right in front of the mesonotum, I (= insertion): 
Fig. 1 SEM micrographs of Claviger testaceus. a dorsal view; b ventral view; $\mathbf{c}$ lateral view. Abbreviations: $\mathrm{cx} 1 / 2 / 3$, pro -/meso-/metacoxal; el, elytron; epp, epipleuron; fem $1 / 2 / 3$, pro -/meso-/metathoracic femur; he, head; n1, pronotum; ohy, outer region of hypomeron; $\mathrm{p} 2 / 3$, meso -/metapleuron; tib1/2/3, pro

-/meso-/metathoracic tibia; $\operatorname{tr} 1 / 2$ 3 , pro-/meso-/metathoracic trochanter

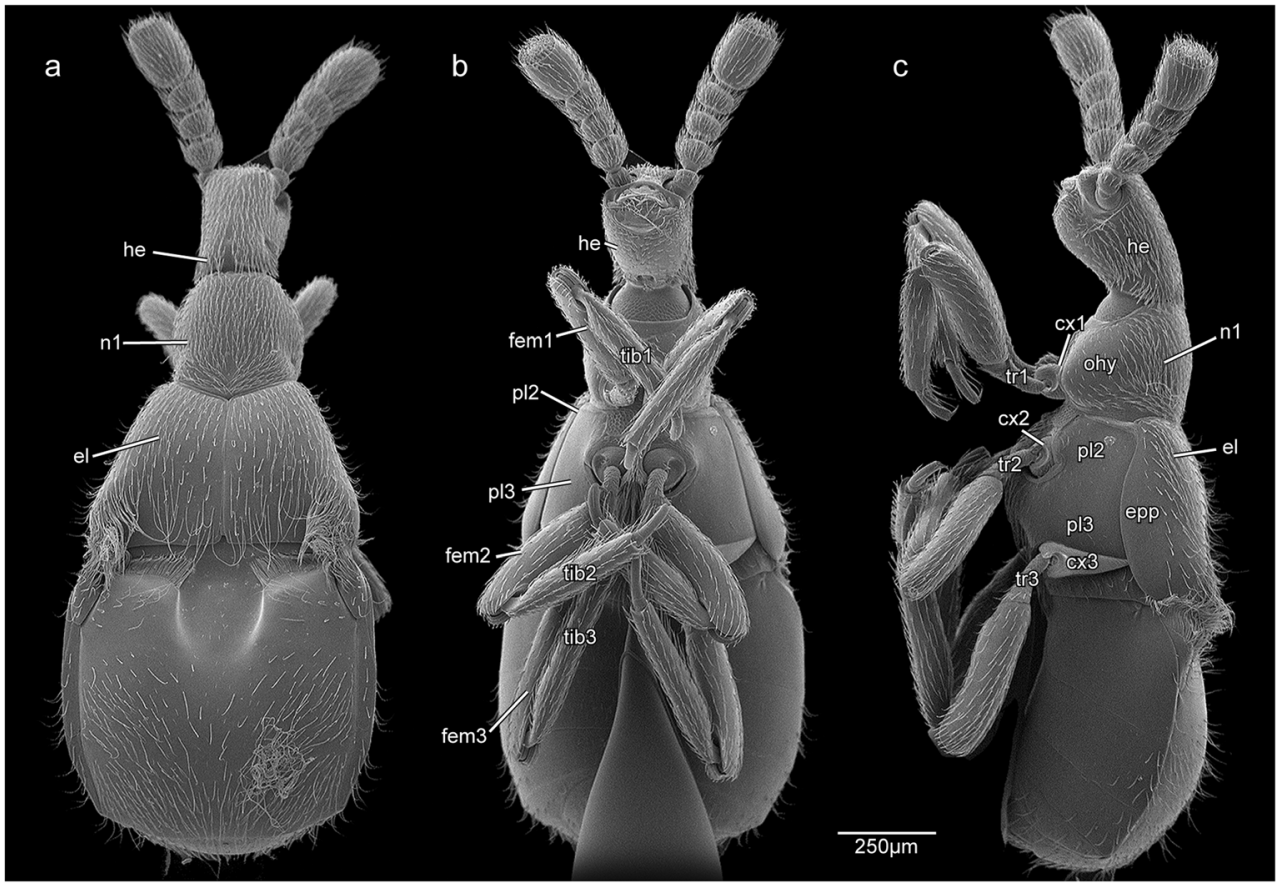

dorsolaterally on the cervical membrane; M3 (M. pronoti tertius) [Idlm3], O: anterolateral mesonotal corner, I: dorsolaterally on the cervical membrane, close to the insertion of M1; M4 (M. pronoti quartus) [Idlm5], O: middle pronotal region, I: anterolateral mesonotal corner; M6 (M. prosterni secundus) [Ivlm1], O: dorsal profurcal tip, I: ventrolaterally on the postoccipital ridge; M9 (M. dorsoventralis tertius) [Idvm5], O: lateral pronotal area, mesad the prothoracic hypomeral depression, I: ventrolaterally on the cervical membrane; M10 (M. dorsoventralis quartus) [Idvm2, 3], O: lateral prosternal area, I: dorsolaterally on the postoccipital ridge; M11 (M. dorsoventralis quintus) [Idvm10], O: anterolateral mesonotal corner, I: dorsal area of the profurca; M12 (M. noto-pleuralis) [Itpm3?; homology uncertain] very short, O: anterolateral pronotal area, I: dorsal side of the apical plate of the cryptopleuron; M13 (M. pronotomesepisternalis) [Itpm6], $\mathrm{O}$ : posterior pronotal region, I: intersegmental membrane between prothorax and mesothorax; M15 (M. noto-coxalis) [Idvm16, 17], two bundles: M15a, O: posterolateral pronotal area, I: mesal procoxal rim; M15b, O: anterolateral pronotal area, I: dorsolateral tip of the procoxa; M19 (M. furca-coxalis) [Iscm2], O: dorsal profurcal area, I: lateral procoxal rim; M20 (M. pleura-trochanteralis) [Ipcm8], O: ventral side of the apical plate of the cryptopleuron, I: trochanteral tendon.

\section{Pterothorax}

\section{Skeleton}

The two pterothoracic segments form an unusually compact structural and functional unit. The lateral and ventral parts of the meso- and metathorax are rigidly connected, with the anapleural suture separating the ventrites from the anepisternal regions completely obliterated. The pleural sutures separating the anepisternal and epimeral parts are also missing in both segments, and the lateral and ventral segmental borders are also obsolete.

The mesonotum is completely concealed below the elytra. Its main part is a T-shaped sclerite, a product of fusion of the transverse main mesoscutal region (sc2, Figs. 2e, 6a) and the mesoscutellum (scl2, Figs. 2e, 3b) including the posterior triangular mesoscutellar shield; this structure has a scale-like retinacular surface; the posterolateral lower mesonotal parts are undifferentiated and unsclerotized, without identifiable notal processes and articulatory elements of the elytra (observation with SEM); the elevated transverse mesoscutal part bears several setae on its anterolateral area; the subtriangular scutellar part forms an acute vertical angle with the remaining sclerite; posteriorly it is elevated just above the median longitudinal groove of the metanotum. The second phragma is vestigial. A short and transverse anterior part of the metanotum is likely the prescutum. The metascutum (sc3, Figs. 2e, 3b, 6a) is by far the largest metanotal element; it is divided by a wide median longitudinal groove (mlg, Figs. 2e, 3b, 6a), delimited by distinct alacristae (alc, Figs. 2e, 3b), which have a scale-like surface structure (Fig. 6a1) and reach the posterior metanotal margin. The short transverse metascutellum (scl3, Figs. 2e, 3b, 6a), separated from the metascutum by a transverse ridge, is medially covered by the alacristae and the enclosed metascutal groove. The third phragma formed by the metapostnotum is present but weakly developed. Axillary sclerites are welldeveloped and could be clearly identified in "long-winged" 
Fig. 2 Line drawings, lightmicroscopy and SEM images of C. testaceus. a. prothorax, dorsal view; b-d prothorax, ventral view; e pterothorax, dorsal view; f-g, pterothorax, ventral view. Abbreviations: alc, alacrista; cc1/ cc2/cc3, pro-/meso-/metacoxal cavity; cx $1 / 2 / 3$, pro-/meso -/metacoxal; fuc $1 / 2 / 3$, pro-/meso -/metafurca; fv, fovea; he, head; hy, hypomeron; hyr, hypomeral ridge; ihy, inner region of hypomeron; mlg, median longitudinal groove; $\mathrm{n} 1$, pronotum; ohy, outer region of hypomeron; pcp, postcoxal process; $\mathrm{pl} 2 / 3$, meso-/metapleuron; psc, prosternal carina; pst, prosternum; ppe, prepectus; $s \mathrm{~s} 2 / 3$, meso -/metascutum; scl2/3, meso -/metascutellum; v2/3, meso -/metaventrite; w, wing
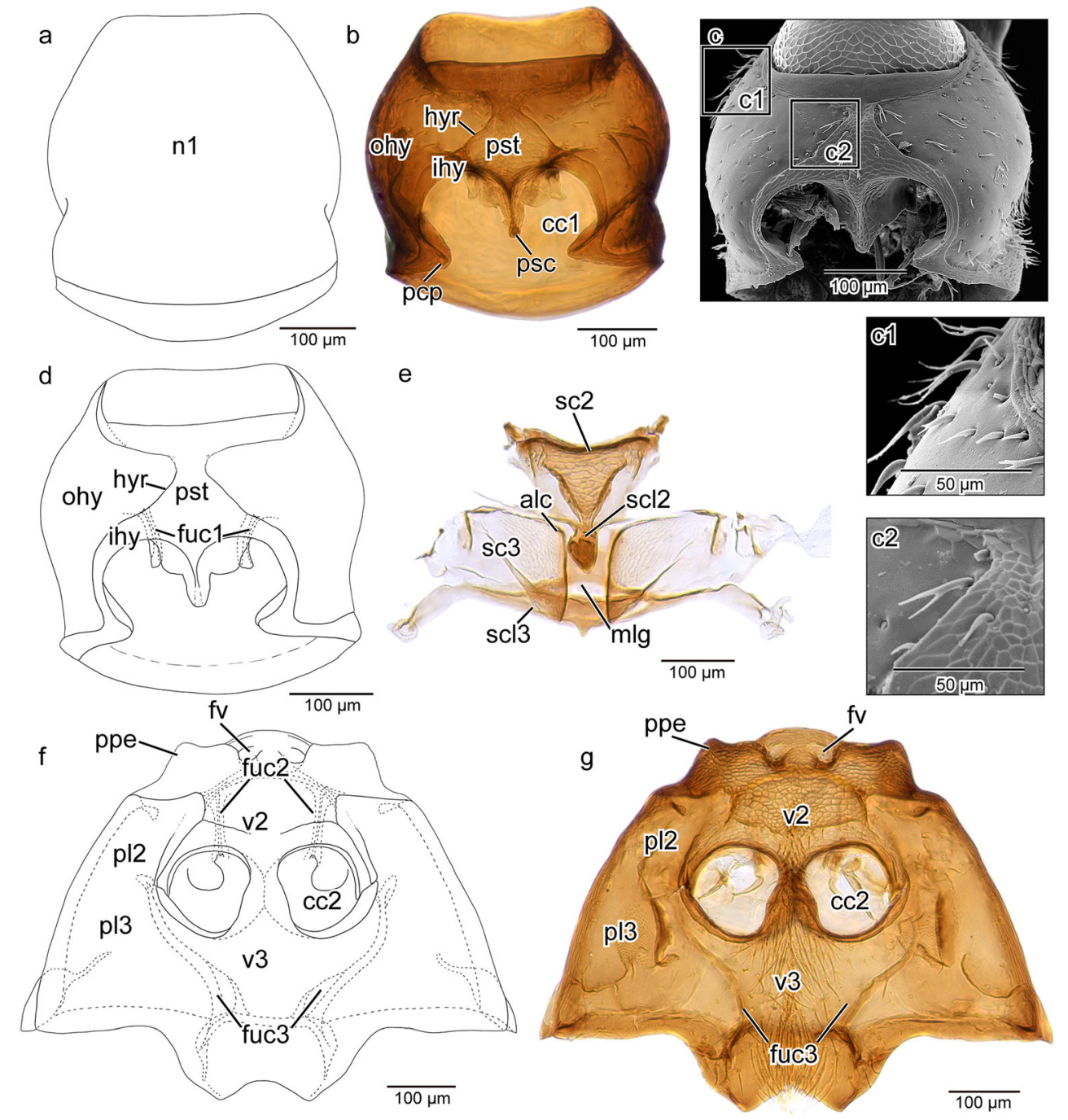

variant I specimens: axillary sclerite 1 (ax1, Fig. 7a) laterad the anterior notal wing process (anp, Fig. 7a) is posterolaterally attached to axillary sclerite 2 (ax2, Fig. 7a); axillary sclerite 3 (ax3, Fig. 7a) is connected to the posterior notal process (pnp, Fig. 7a). Axillary sclerite 1 (ax1, Fig. 6b) in "short-winged" variant II is similar to that of variant I, whereas axillary sclerite 2 and 3 are not recognizable.

The anteriormost part of the ventral and lateral pterothorax forms a wide prepectus (ppe, Figs. 2f-g, 6c-d) with a reticulated surface pattern. The sclerotized mesopleural region posterior to this collar is largely glabrous and forms a concavity dorsally meeting the elytron. The metanepisternum and metepimeron are fused, but the metapleuron (pl3, Figs. 1b-c, 2f-g, 3c-d, 6c-d) comprises two structurally different portions: (1) a lower part, which is strongly sclerotized and completely visible in ventral view, and (2) an inflected upper part, which is membranous or semimembranous and covered by the elytra. A horizontal lateral plate-like protrusion (Fig. 6d1), densely covered with minute plate-like structures on its ventral side, functions as additional elytral locking device. No external suture or ridge demarcating the pleuron from the ventrite is visible. The ratio of the length of the mesoventrite (v2, Figs. $2 \mathrm{f}-\mathrm{g}, 3 \mathrm{c}, 6 \mathrm{c}$ ) and metaventrite (v3, Figs. $2 \mathrm{f}-\mathrm{g}, 3 \mathrm{c}, 6 \mathrm{c}$ ) is approximately $1: 1.5$. Setae cover a longitudinal median area, extending to the posteromedian margin of the metaventrite. A pair of oval foveae (fv, Fig. 2f-g) is present in the anteromedian area of the prepectus, and two shallow depressions are situated in front of the mesocoxal cavities; the median area with the reticulate pattern is posteriorly extended to form the anterior margin of the mesocoxal cavities, with a low longitudinal posteromedian carina. The mesocoxal cavities (cc2, Figs. 2f-g, 3c, 6c-d) are distinctly separated medially; a weakly elevated transverse ridge is present on the middle region of the narrowed intercoxal area, which is narrower than the mesocoxal cavity; the mesotrochantin is concealed. The meso- and metaventrite are almost completely fused; a distinct lateral fissure of the middle region of the mesocoxal cavity is possibly a remnant of the segmental border (visible in Fig. 2f). The smooth metaventrite bears few scattered setae laterally and some longer ones on the median area; a pair of obtuse 


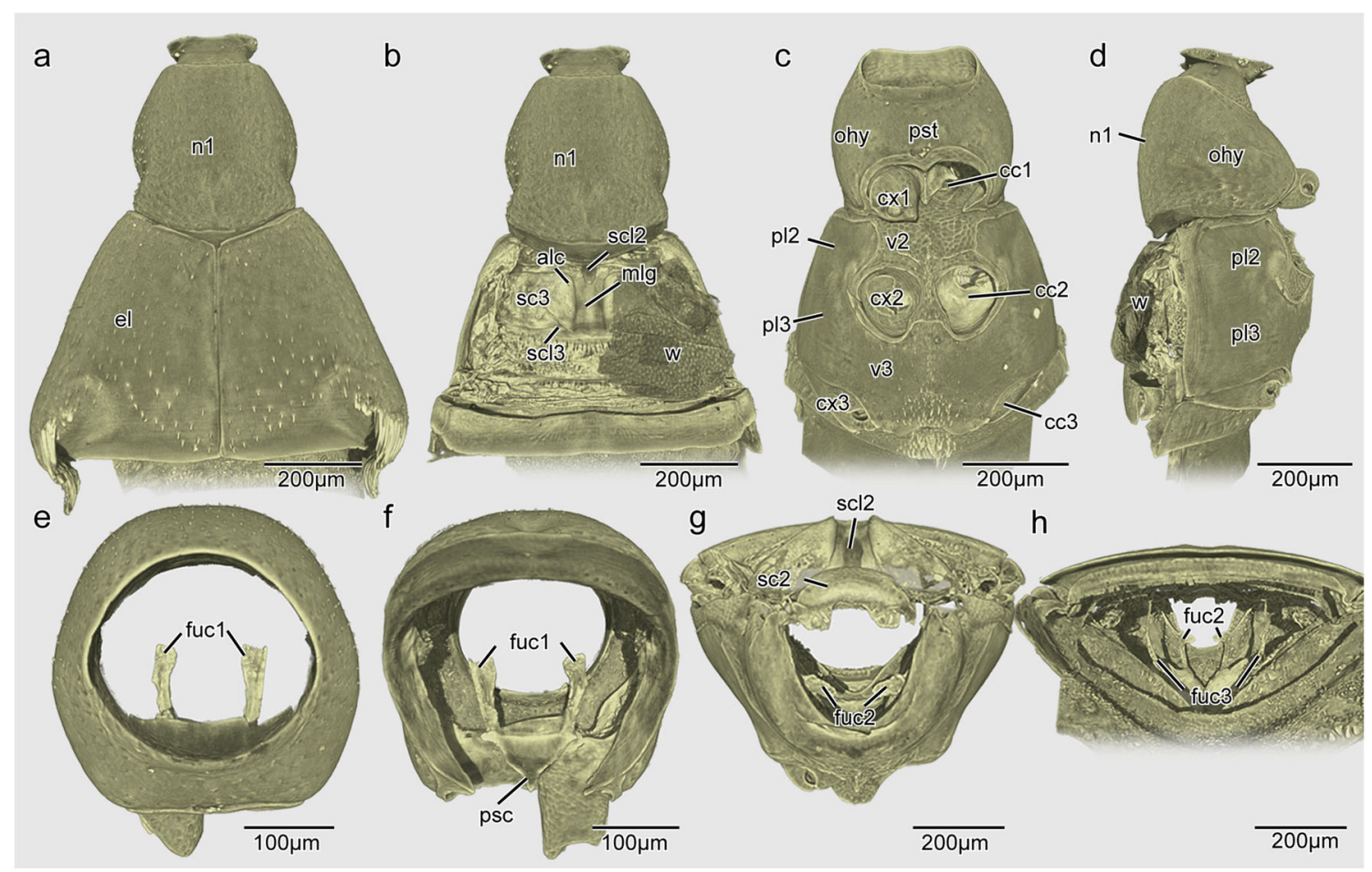

Fig. 3 3D reconstructions of C. testaceus. a thorax (elytra incl.), dorsal view; b thorax (elytra removed), dorsal view; c thorax, ventral view; d thorax, lateral view; e prothorax, anterior view; f prothorax, posterior view; g pterothorax, anterior view; $\mathbf{h}$ pterothorax, posterior view. Abbreviations: alc, alacrista; $\mathrm{cc} 1 / \mathrm{cc} 2 / \mathrm{cc} 3$, pro-/meso-/metacoxal cavity;

processes on the posteromedian margin forms a reverse $\mathrm{V}$ shaped median emargination. The transverse metacoxal cavities (cc3, Figs. 3c, 6c-d) are distinctly separated from each other.

The well-developed mesofurcal arms (fuc2, Figs. 2f, 3g-h) are basally separated from each other; the basal part is relatively wide and bent anterad; a plate is present in the middle region of each arm; the distal portion of the arms is narrowing towards the dorsolateral region of the segment and ends laterad the mesonotum. The rod-like and sinuate metafurcal arms (fuc3, Figs. $2 \mathrm{f}-\mathrm{g}, 3 \mathrm{~h}$ ) are also basally separated and form a nearly right angle with the ventrite; they taper dorsally and end with a small plate-like tip for muscle attachment close to the metanotum. A low internal anapleural ridge (apr, Fig. 5c) is present laterally; it delimits the boundary between ventrite and pleuron; this structure extends from a site laterad the mesocoxal cavity to the area anterior to the metacoxal cavity.

The trapezoidal elytra (el, Figs. 1a, c, 3a) bear a narrow bead along their anterior margin. Approximately right angles are formed basolaterally (humeral angle) and posteromedially, whereas the posterolateral corner is evenly arcuate and the anteromedian angle obtuse. The elytra are distinctly longer than the pronotum along their mesal edge and also distinctly wider. The setation of the dorsal side of the elytra is less dense than that on the pronotum, and the setae are evenly arranged in longitudinal rows; the setae with bifurcate tips on the anterior cx1/2/3, pro-/meso-/metacoxa; el, elytron; fuc $1 / 2 / 3$, pro-/meso -/metafurca; ohy, outer region of hypomeron; mlg, median longitudinal groove; $\mathrm{n} 1$, pronotum; $\mathrm{pl} 2 / 3$, meso-/metapleuron; psc, prosternal carina; pst, prosternum; sc2/3, meso-/metascutum; sc12/3, meso -/metascutellum; v2/3, meso-/metaventrite; w, wing

region are distinctly shorter than those with a single tip on the posterior region; the posterolateral corner bears a dense, conspicuous tuft of long setae. No carinae or punctures are present on the dorsal surface, and impunctate impressed striae along the sutural margin are also lacking. The largely glabrous epipleuron (epp, Fig. 1c) is broad and well-visible in ventral view, with a smooth and convex ventral margin; it is gradually widening, reaching the maximum width in the middle area and is then moderately narrowing towards the posterior end; an epipleural keel is missing. The internal surface of the ventral side of the elytra (Fig. 7) is largely smooth and glabrous. The lateral rim is also mostly glabrous, but digitiform structures are present at the anterior corner (Fig. 7f), and low longitudinally arranged ridges (Fig. $7 \mathrm{~g}$ ) are present; the posterior area is covered with scale-like structures, with or without short microtrichia (Fig. 7h, i); the mesal rim is smooth in the middle region but covered with scales on its anterior (Fig. 7k) and posterior (Fig. 7 j) areas; a medially protruding lamella (lal, Fig. $7 \mathrm{e}, 8 \mathrm{c}, \mathrm{f}$ ) originates at the humeral angle; it extends along the lateral rim and is about $2 / 3$ as long; it is inserted onto the membranous inflection of the pleuron. The anteromesal edges of the elytra form a tunnel-shaped cavity covering the mesoscutellar shield.

The hind wings (w, Figs. 3b, 6a, 7b-d) are strongly shortened and non-functional; they show some variability with two distinctly different forms: variant I (Figs. 6a, 7b-d) is a wing 


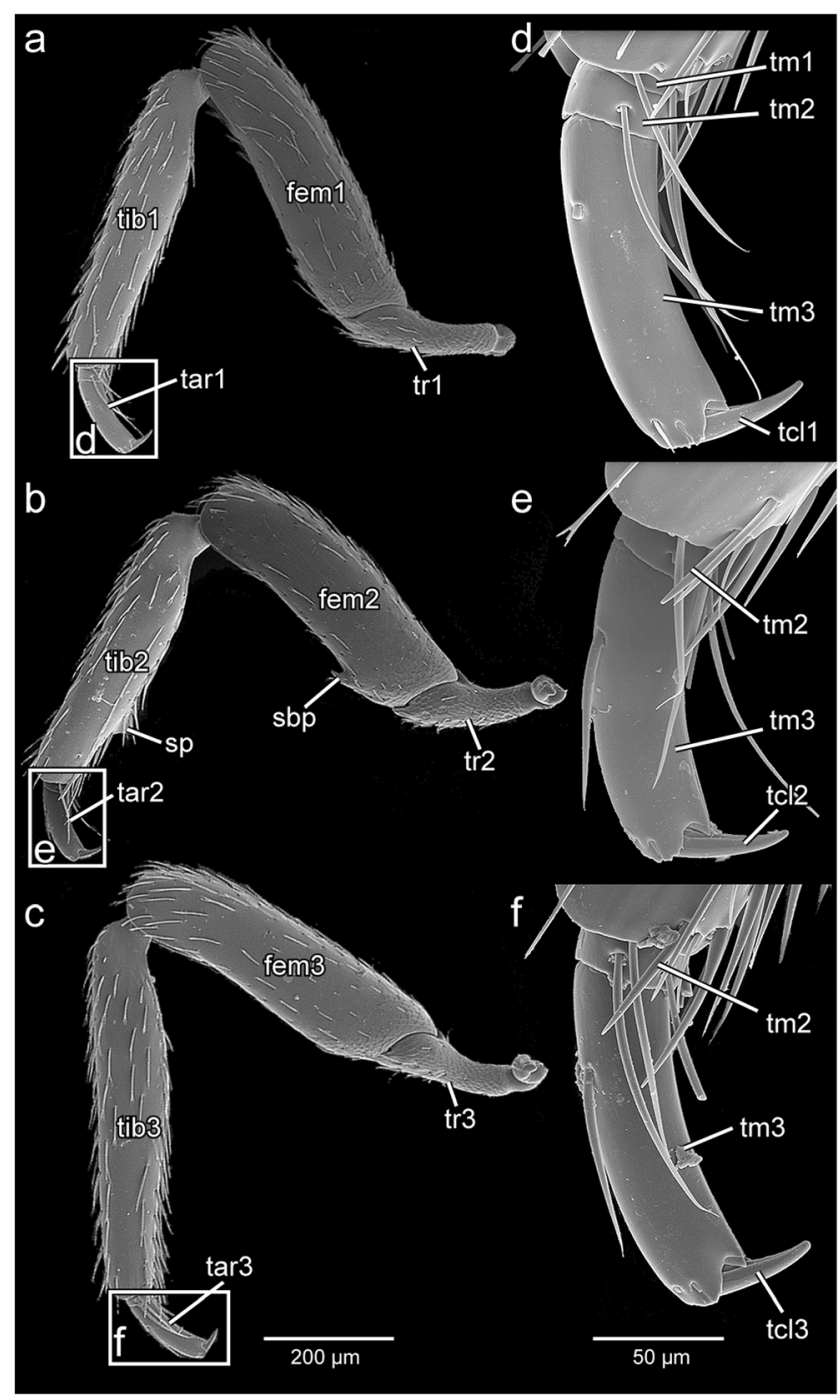

Fig. 4 SEM micrographs, legs of $C$. testaceus. a foreleg; b midleg; c hindleg. Abbreviations: fem $1 / 2 / 3$, pro-/meso-/metathoracic femur; sbp, sub-basal projection; sp, submedian projection; tm1-3, tarsomere 1-3; $\operatorname{tar} 1 / 2 / 3$, pro-/meso-/metathoracic tarsus; tcl1/2/3, pro-/meso-/metathoracic pretarsal claw; tib1/2/3, pro-/meso-/metathoracic tibia; $\operatorname{tr} 1 / 2 / 3$, pro $-/$ meso-/metathoracic trochanter

rudiment folded six times transversely, with no longitudinal folds; when folded it is about twice as long as the metanotum (it was not possible to unfold the wing during dissection in water); a relatively large anterior proximal area is sclerotized (Fig. 7c), and the entire wing membrane is very densely covered with long microtrichia, except for two small areas near the wing base; variant II (Fig. 6b1) is barely recognizable as a wing rudiment and shorter than the metanotum; it is irregularly crumpled and folded below the elytron; a proximal sclerotization similar to that of variant I is present; the membranous portion is much shorter but also densely covered with microtrichia.

The general shape of the middle and hind legs (Figs. 1b-c, $4 \mathrm{~b}-\mathrm{c}$ ) distad the coxae is similar to that of the forelegs, except for the presence of a ventral sub-basal projection (sbp, Fig.4b) on the femur and a ventral submedian projection (sp, Fig. 4b) on the mesotibia of males. The mesocoxa (cx2, Figs. 1c, 3c) is subglobose, without a large internalized part. The middle leg (excluding the coxa) is approximately $1.25-\mathrm{mm}$ long. The ratio of trochanter/femur/tibia/tarsus is around 1.8/3.6/3.8/1. The transverse metacoxae (cx3, Figs. 1c, 3c) bear a welldeveloped coxal plate with an oblique posterior face. The hind leg (excluding the coxa) is approximately $1.4 \mathrm{~mm}$ long; the ratio of trochanter/femur/tibia/tarsus is around 1.7/3.3/4.1/1. Tarsomere 1 of the meso- and metatarsi (Figs. 4e, f) appears hidden below the distal tibial margin (in SEM images); tarsomere 1 is well visible (in transparent mounts, not shown here) and similar to that of the protarsus and to tarsomere 2 .

\section{Musculature (Fig. 5)}

Mesothorax: M28 (M. mesonoti primus) [IIdlm1], very weakly developed, O: on the middle region of the highly reduced mesophragma, I: on the prophragma directly laterad the median line; M30 (M. mesoterni primus) [Ivlm7], O: anterior side of the small mesofurcal plate, I: dorsally on the profurca; M37 (M. furca-pleuralis) [IIspm2], very short, O: dorsal tip of the mesofurcal arm, I: on the middle region of the uppermost pleural area; M40 (M. noto-coxalis) [IIdvm5, 4?], O: anterolateral mesonotal corner, I: posterior mesocoxal rim; M41 (M. episterno-coxalis) [IIpcm4], O: large part of the mesanepisternal region (anterior pleural area), I: anterior rim of the mesocoxa; M44 (M. furca-coxalis anterior) [IIscm1], O: lower part of the mesofurca, posterior to the insertion of M30 on the mesofurcal plate, I: anterior mesocoxal rim; M46 (M. furca-coxalis posterior) [IIscm2], O: posterior side of the mesofurcal plate, I: posterior mesocoxal rim; M48 (M. episterno-trochanteralis) [IIpcm6] /M49 (M. epimerotrochanteralis), O: dorsally on the upper pleural area, I: trochanteral tendon, together with M52; M52 (M. furcatrochanteralis) [IIscm6], O: lateral area of the mesofurcal arm, I: trochanteral tendon, together with M48/M49.

Metathorax: M65 (M. dorsoventralis secundus)/M66 (M. dorsoventralis tertius) [IIIdvm8], O: posterolateral metanotal area, I: dorsal tip of the metafurcal arm; M71 (M. pleuraalaris)? [IIItpm9, 7?], O: semimemberanous area of the pleural middle region (arguably epimeral part), I: anteriorly close to the wing base (exact attachment site not clearly visible); M72 (M. sterno-episternalis) [IIIppm1], wide and flat, O: dorsally along the inflected structure of the largely membranous pleural area (arguably epimeral part), I: ventrally along the internal anapleural ridge; M76 (M. noto-coxalis posterior) [IIIdvm5], O: lateral area of the metanotum, I: posterior metacoxal rim; M77 (M. episterno-coxalis) [IIIpcm4], O: inflected sclerotized structure of the pleuron, posterior to the origin of M72, I: anterior metacoxal rim; M81 (M. furca-coxalis anterior) [IIIscm1], O: basal metafurcal part, I: anteromedian metacoxal 


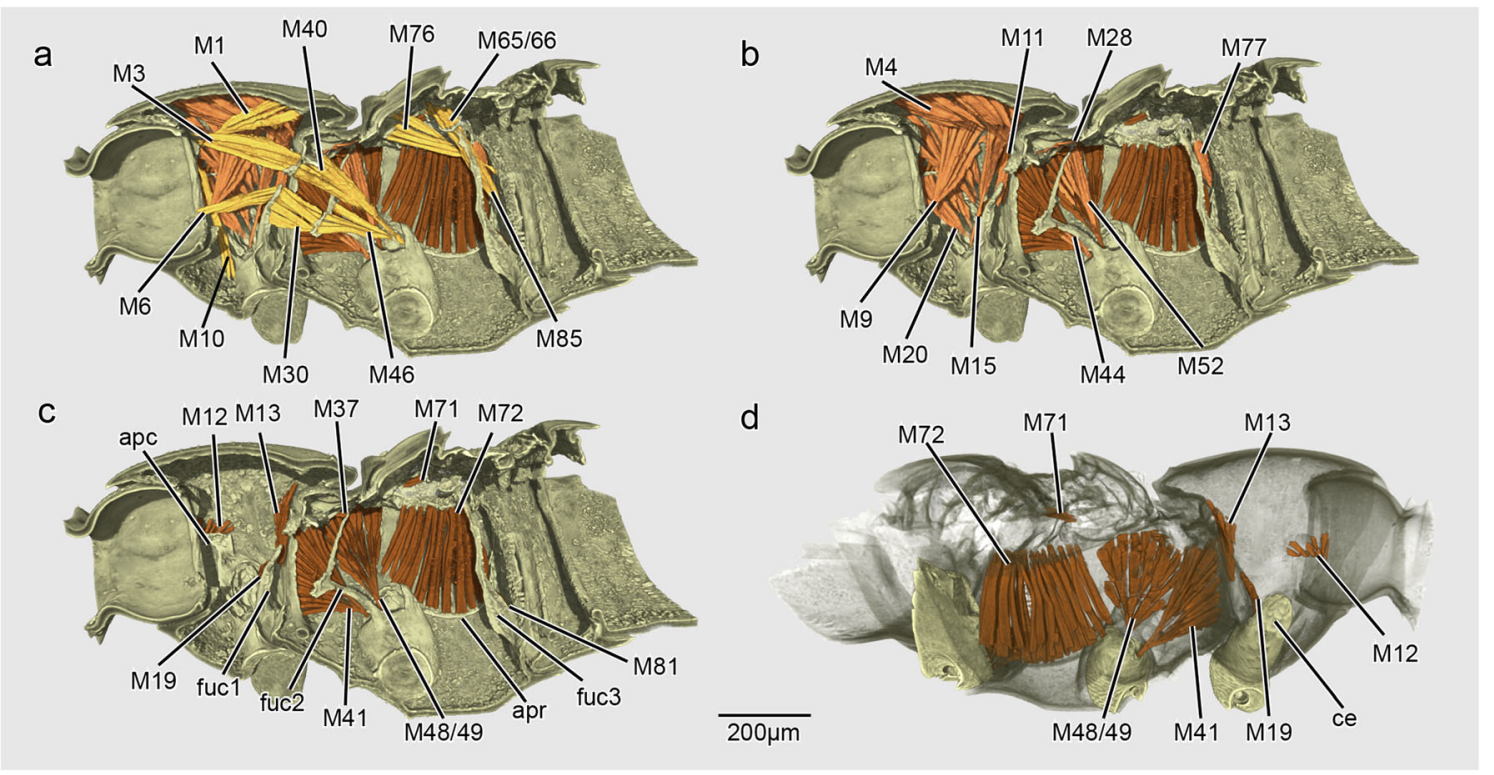

Fig. 5 3D reconstructions of thoracic muscles of C. testaceus. a-c mesal view; d lateral view. Abbreviations: apc, apical plate of the the cryptopleuron; apr, anapleural ridge; ce, concealed lateral extension; fuc1/2/3, pro-/meso-/metafurca. For abbreviations of muscles please see the description

rim; M85 (M. furca-trochanteralis) [IIIscm6], O: dorsal tip of the metafurcal arm, I: trochanteral tendon.

\section{Anterior abdominal segments}

\section{Skeleton}

The abdominal tergites I-III are completely covered by the elytra. Tergites I and II (atI, atII, Fig. 6a) are about equally long and largely membranous; the well-sclerotized tergite III (atII, Fig. 6a) is distinctly longer than each of them; its anterior part is almost completely covered by low ridges, scales, and short setae, whereas the posterior portion is smooth; a tuft of short setae is present on the lateral margin. Tergite III is posteriorly adjacent with the fused tergites IV-VI. Abdominal sternites I and II are not present as identifiable individual structures, completely membranous and not visible externally. Sternite III (asIII, Fig. 6d) is strongly sclerotized, with an anterior bead forming the posterior margin of the metacoxal cavity; posteriorly it is attached to sternite IV (asIV, Figs. 6d, 8 ); a dense tuft of long setae is present on the median area of sternite III, and some additional setae are sparsely distributed on the lateral regions.

\section{Musculature (Fig. 9)}

All muscles of the anterior abdominal segments described here have a longitudinal orientation; some additional small bundles or fibers are present but could not be clearly identified with our data set. Ma1, O: anterior margin of tergite I; I: fold between tergite I and II; Ma2, O: broadly on the fold between tergites I and II; I: fold between tergites II and II; Ma3, O: fold between tergites II and III; I: posterior phragma of abdominal tergite III; Ma4, O: along the metafurcal edge, ventrally near the base and dorsally reaching about $2 / 3$ of the entire length of the furca, I: region of the strongly reduced abdominal sternite I; Ma5, O: ventrally on the region of the reduced abdominal sternite I, I: region of the membranous abdominal sternite II; Ma6, O: region of abdominal sternite II, I: posterior margin of abdominal sternite III.

\section{Discussion}

\section{Phylogenetic background}

Pselaphinae were for a long time regarded as a separate family (e.g., Akre and Hill 1973), but were convincingly identified as a subgroup of the megadiverse Staphylinidae (e.g., Newton and Thayer 1995). Newton and Thayer (1995) presented a comprehensive morphological study of the Omaliine group, one of the major lineages of rove beetles, also including Protopselaphinae and Pselaphinae as sister taxa. They emphasized a high level of homoplasy and events of parallel evolution in different subunits (Table 1). One important apomorphic feature of the Omaliine group is (1) the absence of the suture separating the mesoventrite and mesopleuron (Character 61 of Newton and Thayer 1995 [in the following abbreviated as N\&Th]). Several potential synapomorphies of the Pselaphine lineage (i.e., Neophoninae, Dasycerinae, Protopselaphinae, and Pselaphinae), a subunit of the Omaliine group, were suggested by Newton and Thayer 


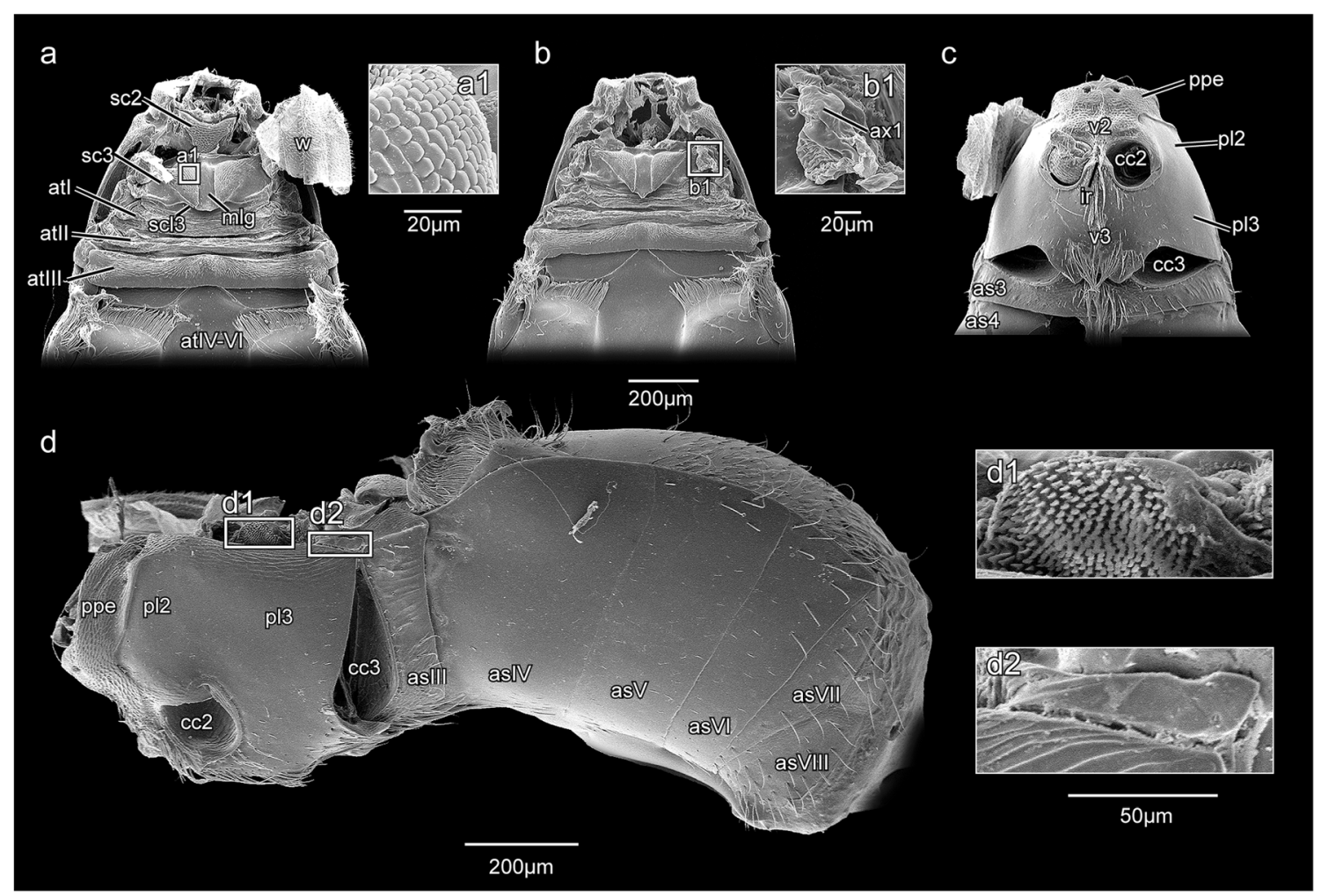

Fig. 6 SEM micrographs, pterothorax of C. testaceus. a "long-winged" (variant I) individual, dorsal view; b "short-winged" (variant II) individual, dorsal view; c ventral view; d lateral view. Abbreviations: asIII - VIII, abdominal sternite III - VIII; atI - VI, abdominal tergites I - VI; ax1, axillary sclerite $1 ; \mathrm{cc} 2 / \mathrm{cc} 3$, pro-/meso-/metacoxal cavity; $\mathrm{mlg}$, median longitudinal groove; pl2/3, meso-/metapleuron; ppe, prepectus; sc2/3, meso-/metascutum; scl2, mesoscutellum; v2/3, meso-/metaventrite

Obviously, several changes that took place in the early evolution of the subfamily do not remain constant in the supertribe Clavigeritae. An additional structural simplification was interpreted as potential synapomorphy of Pselaphinae excluding Faronitae by Newton and Thayer (1995): (13) the absence of the mesopleural ridge ("sulcus") (Fig. 6d) (Ch. 63 N\&Th).

Even though Clavigeritae are obviously highly specialized, the group is not characterized by a single unique and nonhomoplasious thoracic apomorphy. Even the conspicuous elytral trichomes can be absent in some members of this group (e.g., Hlaváč 2005). Nevertheless, the monophyly appears well-supported by several derived thoracic features: (16) secondary absence of foveae on the metaventrite (Figs. 1b, 6c) (Ch. 6 N\&Th), (17) absence of the transverse antebasal pronotal impression (Fig. 1a) (Ch. $53 \mathrm{~N} \& \mathrm{Th}$ ), (18) absence of the suture separating the mesepimeron from the metaventrite (Fig. 6d) (Ch. 65 N\&Th), (19) elytra with a straight apex or evenly arcuate near the lateral margin (Fig. 1a, 7e) (Ch. $71 \mathrm{N \& Th}),(20)$ the presence of only a single claw (Fig. 4) (Ch. 81 N\&Th), and (21) a long mesotrochanter (Fig. 4b) (Ch. $84 \mathrm{~N} \& \mathrm{Th}$ ), with the entire femoral base distinctly separated from the coxal cavity.

Characters 55, 56, 60,61, 63, and 65 of Newton and Thayer (1995) (corresponding to chars. 6, 7, 2, 1, 13, and 18 in the text above and Table 1) are part of an evolutionary trend the anteromedian region of the mesoventrite (fv, Fig. $2 f$, g). 
Fig. 7 Hind wings of variant I a$\mathbf{d}$, in dorsal view and elytra $\mathbf{e}-\mathbf{k}$, in ventral view of $C$. testaceus.

Abbreviations: anp, anterior notal process; ax1-3, axillary sclerite 1-3; lal, lateral lamella; pnp, posterior notal process
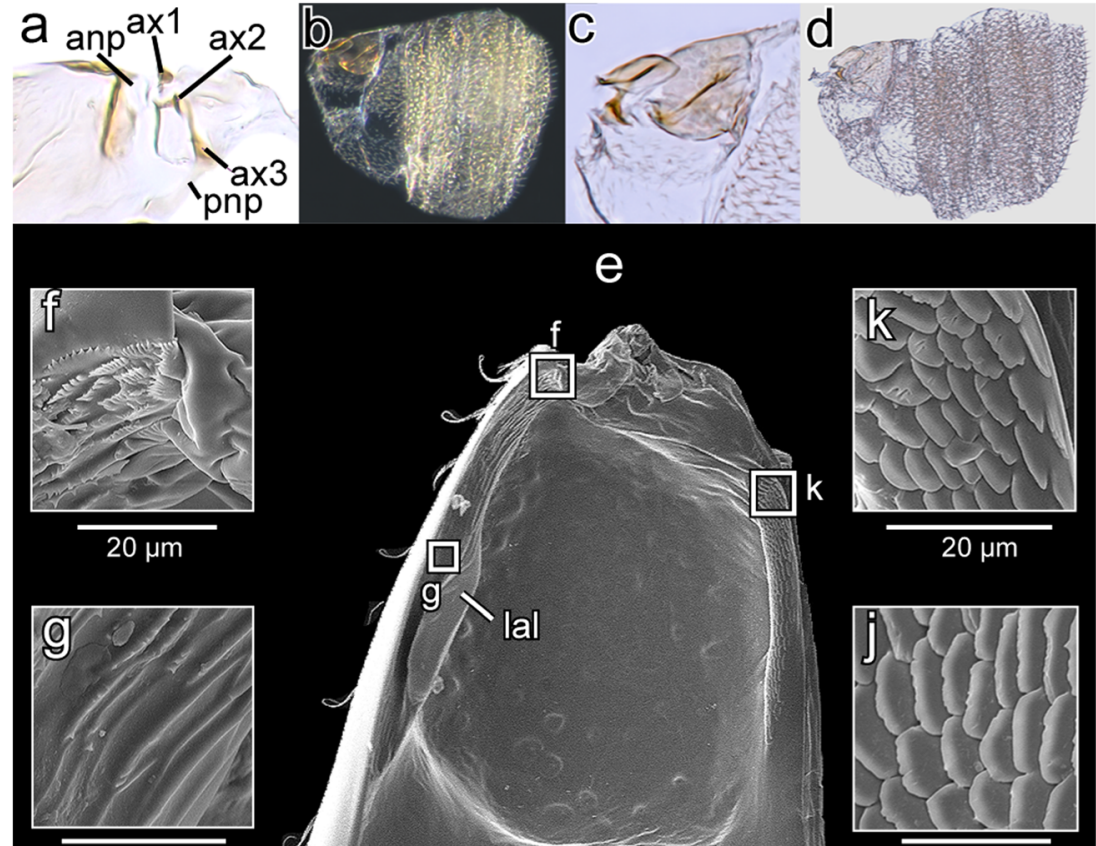

$20 \mu \mathrm{m}$

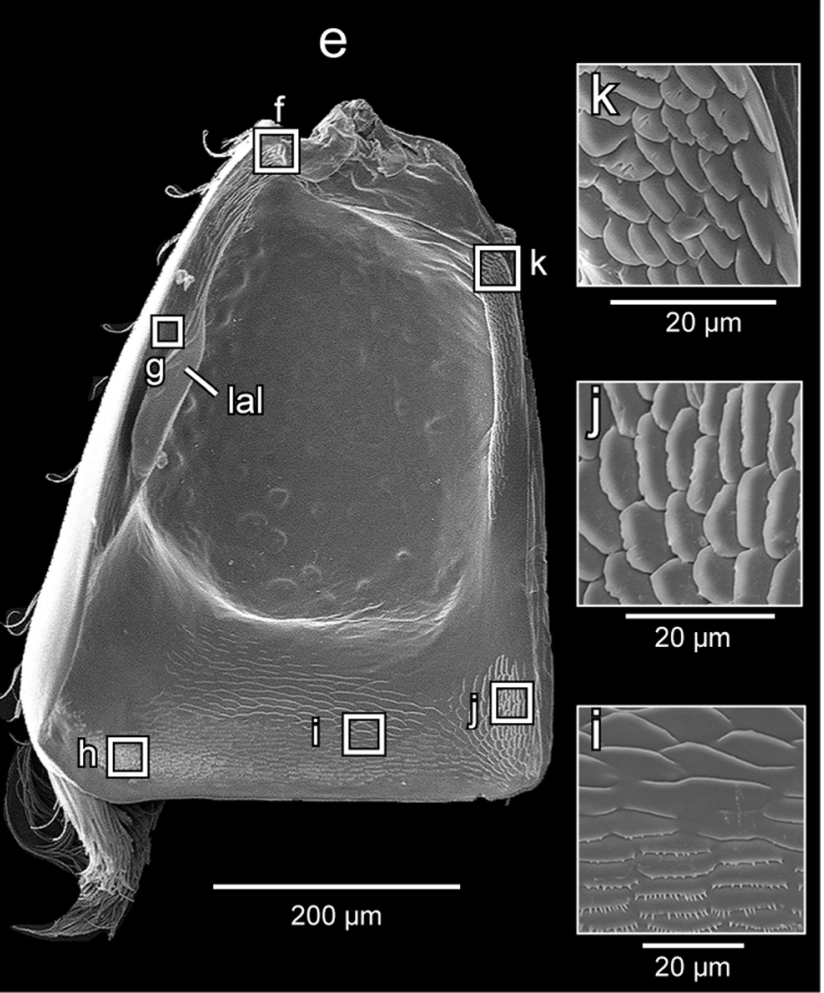

in the Omaliine group, leading to different degrees of fusion and an increasing mechanical stabilization of the thorax in several stages, and apparently reaching a maximum in Clavigeritae. Obviously, these features did not evolve as adaptations to myrmecophily, as they also occur in groups lacking this specialized life style. However, a compact and robust thorax was likely a pre-adaptation for an association with ants. It was obviously advantageous for myrmecophiles, offering improved mechanical protection (Parker 2016a).

An interesting feature of the prothorax is the long and concealed lateral extension of the procoxa (ce, Fig. 5d), a modification that has apparently evolved independently in several pselaphine groups including Clavigeritae and also in other subfamilies of Staphylinidae outside of the Omaliine group (e.g., Steninae, Euaesthethinae, Osoriinae [part.] (Lawrence and Ślipiński 2013; Thayer 2016). It is conceivable that this contributes to the general mechanical protection of the thorax. However, the precise functional background is largely unclear at present.

The ventral prothoracic configuration of $C$. testaceus is similar to what is found in other (free-living and predatory) pselaphines (Fig. S1), with open procoxal cavities and the prosternum fused with the hypomera. However, it differs in the absence of foveae. The ventral prothoracic foveae occurring in Pselaphinae are typically situated in front of the procoxal cavities and/or on a lateral longitudinal hypomeral groove found in many species (Fig. S3a-e). The hypomeral groove is absent in Claviger (Fig. 2b-d) and also in Pselaphus (Fig. S1f), a member of Pselaphitae, which in recent phylogenetic analyses consistently clusters together with Clavigeritae (Parker 2016b; Parker and Grimaldi 2014). However, the groove is also absent in Protopselaphinae, arguably in this case a plesiomorphic condition. Apparently, the presence or absence of this concavity varies strongly within the group. It is likely absent in the groundplan of Protopselaphinae + Pselaphinae and may have been acquired and secondarily lost several times in the latter group. A feature of the prothorax of Claviger distinguishing it from that of other pselaphines is the expansion of the anterior half of the hypomera towards the midline, thus distinctly narrowing the prosternal area (Fig. $2 \mathrm{c}-\mathrm{d}$ ). As a prosternum fully separated from the hypomera by notosternal sutures (as in Fig. 10a) is part of the groundplan of Coleoptera (e.g., Beutel and Haas 2000) and very likely also of Staphylinidae (Newton and Thayer 1995), a scenario can be proposed to explain transformations leading to the condition observed in Claviger (Fig. 10a-d). In the first stage, 


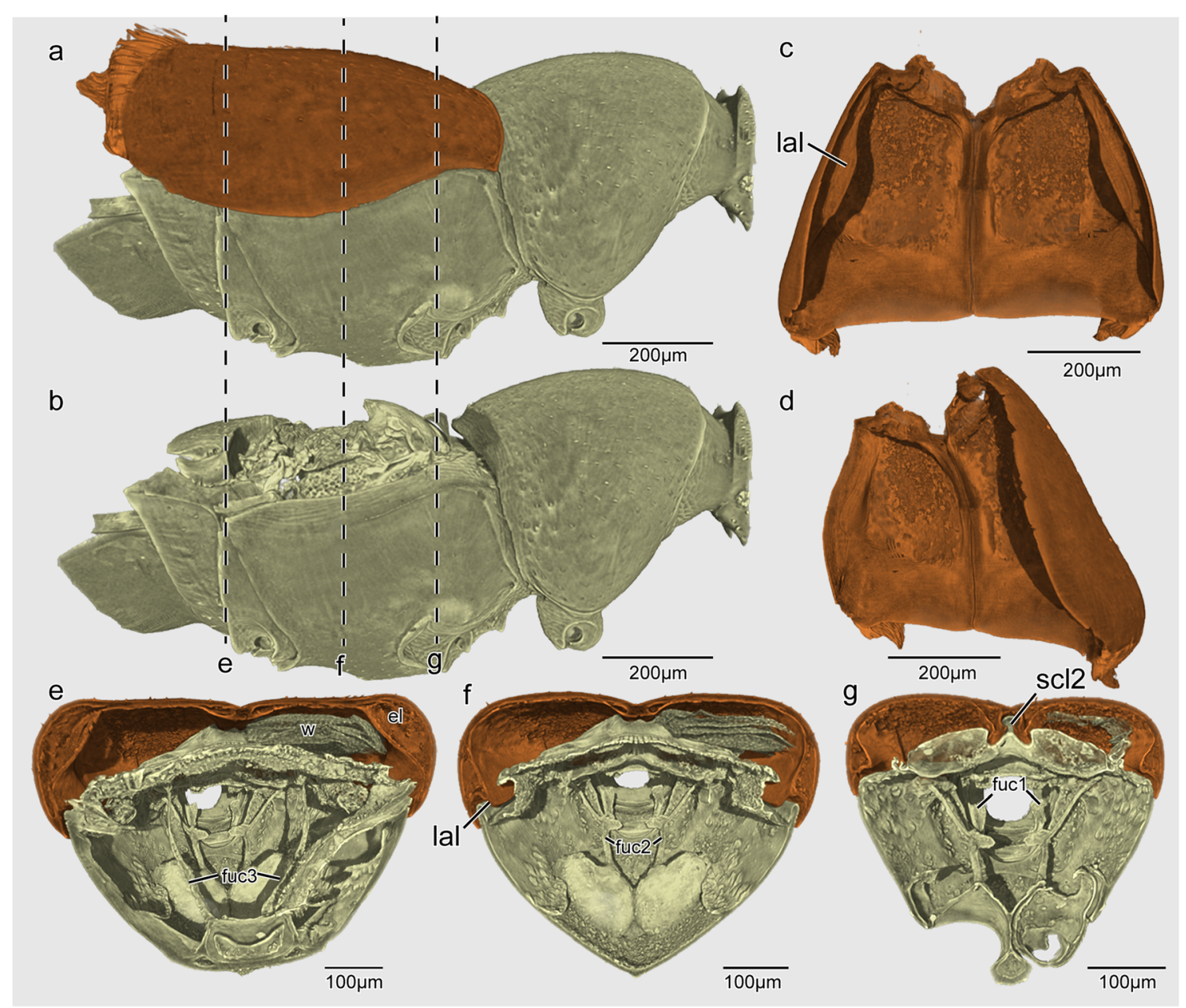

Fig. 8 3D reconstruction of $C$. testaceus. a-b thorax, lateral view; c-d elytra; e-g thorax, posterior view. Abbreviations: el, elytron; fuc1/2/3, pro-/meso -/metafurca; lal, lateral lamella; scl2, mesoscutellum; w, wing

hypomeral ridges develop, which reinforce the prothorax mechanically (Fig. 10b); this process results in a division of the hypomera into an outer part (ohy, Fig. 10b), which is continuous with the lateral and dorsal pronotum, and a narrow longitudinally extending inner part (ihy, Fig. 10b). In the next step, the notosternal sutures (or connecting membranes) are reduced and the prosternum fuses with the inner hypomeral part on both sides (Fig. 10c); this condition is typical for Pselaphinae, but the notosternal sutures are reduced to various degrees, and hypomeral ridges can be also found among nonrelated scydmaenines (e.g., Jałoszyński 2020); vestiges of notosternal sutures occur in species of both subfamilies, either visible in transparent mounts only (internalized notosternal sutures; irns, Fig. S1a) or as short notches on the anteroventral prothoracic margin (e.g., Jałoszyński 2018). As a final transformation, the mesally expanding hypomera distinctly narrow the prosternal region (Fig. 10d), a process resulting in the unusual condition seen in C. testaceus (Figs. 2c-d).

The presently available data on internal skeletal structures and muscles of Pselaphinae are too scarce for a systematic evaluation. Some information on skeletal elements was provided by Lawrence and Ślipiński (2013). Nomura (1991) described the pro- and mesofurcae in the Batrisocenus complex of the supertribe Batrisitae, which are similar to the homologous structures of $C$. testaceus, and therefore possibly close to the groundplan condition in the subfamily. The metafurcae of Batrisceniola semipunctulata (Raffray, 1909) and Batrisoschema euplectiforme (Sharp, 1883) were not explicitly described in text but were illustrated with line drawings (Nomura 1991: Fig. 18A, B). As they converge basally and lack a median plate extending from the arms, they differ distinctly from the metafurca of $C$. testaceus. The internal anapleural ridge delimitating the metaventrite and metapleuron was not documented for any pselaphine species so far.

\section{Musculature}

This first detailed anatomical investigation of a pselaphine species revealed some interesting traits of the thoracic musculature. It is obvious that multiple muscle losses or partial reductions observed in C. testaceus are more or less directly 
Fig. 9 3D Reconstruction of longitudinal abdominal muscle. Abbreviations: apr, anapleural ridge; asI - III, abdominal sternite I - III; fuc2/3, meso-/metafurca; For abbreviations of muscles see description

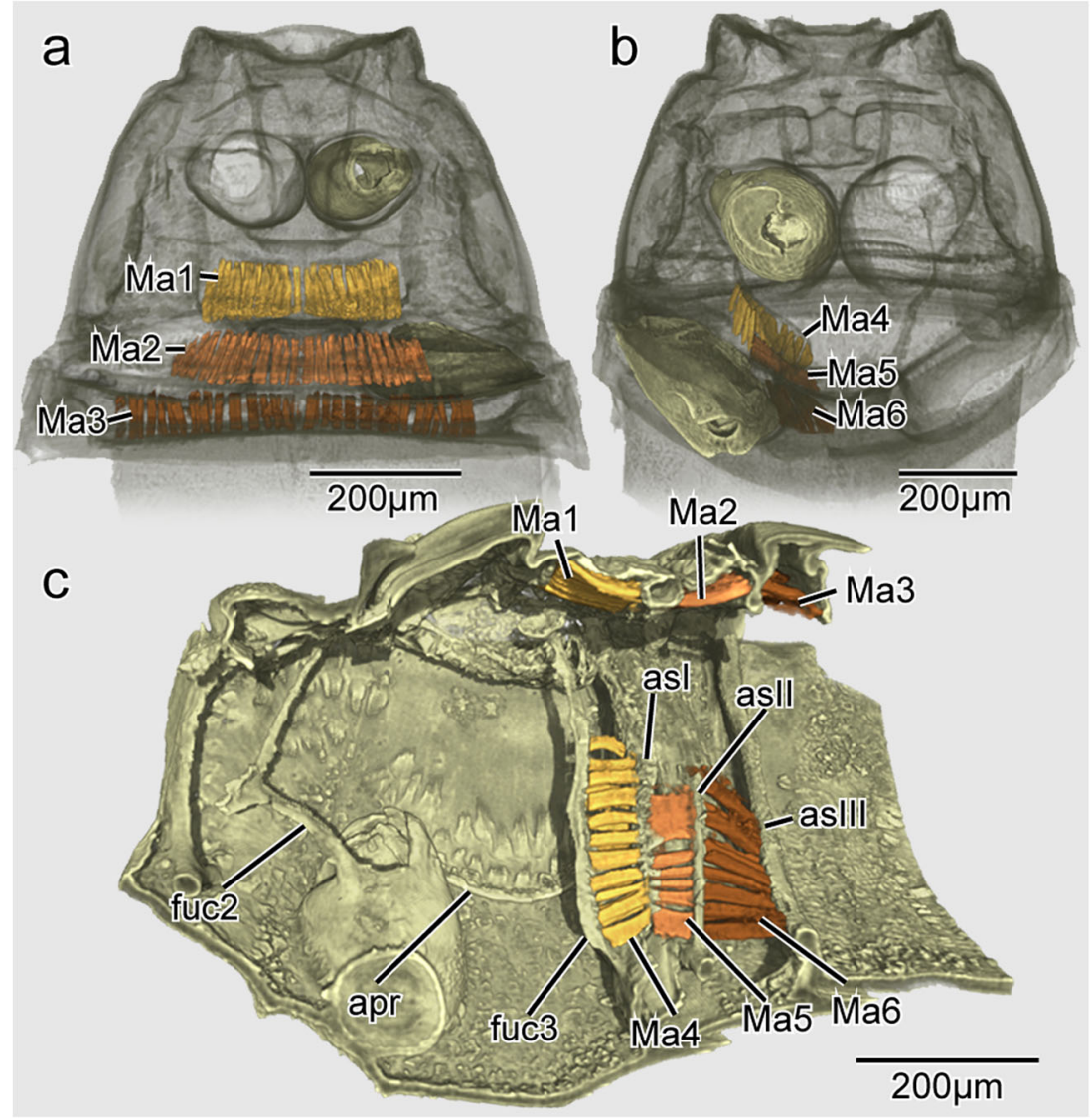

linked to flightlessness, with the exception of the weaklydeveloped M28 (M. mesonoti primus). The homology of the presumptive M71 (M. pleura-alaris) remains ambiguous, due to far-reaching skeletal modifications. The almost complete loss of direct flight muscles is obviously linked with profound simplifications of skeletal elements linked with flight, for instance, the absence of the basalar muscle disc or a defined subalare. The presence of a single bundle likely equivalent with combined muscles M65/M66 is a feature shared with the cave-dwelling leiodid Troglocharinus ferreri (Reitter, 1908) (Luo et al. 2019), apparently a result of parallel evolution related to flightlessness. It is noteworthy that $C$. testaceus lacks more dorsal and ventral muscles (M2 and M5 in the prothorax, M62 in the metathorax) than T. ferreri (Luo et al. 2019). This is arguably linked with the increased mechanical compactness of the prothorax and pterothorax. Another derived feature is the fusion of M48 and M49, likely associated with the fusion of anepisternal and epimeral elements in the mesothorax of $C$. testaceus. A comparison of the thoracic musculature of three species of Staphylinoidea is presented in Table 2, including the cryptic and flightless C. testaceus and T. ferreri (Leiodidae) (Luo et al. 2019), and the unspecialized, large, diurnal predator Creophilus maxillosus (Linnaeus, 1758) (Staphylininae) (Larsén 1966).

\section{Elytral locking system and flightlessness}

Elytral fixation mechanisms are a specific and complex characteristic of Coleoptera. The locking devices formed by the mesoscutellar shield and the metanotal alacristae (Klima 1983) are very likely a groundplan feature of the Order (Friedrich et al. 2009). A remarkable array of additional fixation devices has evolved within the group, especially frictional surfaces, a character system evaluated in detail in the family Tenebrionidae (Gorb 1998).

An extreme case of mechanical strengthening of the elytral body cover occurs in the "diabolically ironclad beetle" Nosoderma diabolicum LeConte (Zopheridae, Tenebrionoidea) (Rivera et al. 2020). Another unique and enhanced type of locking system has evolved in Pselaphinae, arguably a key feature in the evolution of this successful subfamily. The involved structures of Batrisocenus complex (Batrisitae) were documented by Nomura (1991), suggesting a general similarity with the condition observed in the species we examined. The most noteworthy features observed in C. testaceus are the following: (1) well-developed lateral elytral lamella (lal, Fig. 7e) interacting with the inflected semimembranous pleural area; (2) a tunnel-shaped structure formed by the mesal elytral bases and enclosing the elevated mesoscutellar shield (Fig. 8g); and (3) the distinct anterolateral 
Table 1 Phylogenetically informative thoracic characters of supertribe Clavigeritae extracted from Newton and Thayer (1995), with updated morphological nomenclature. Numbers in round brackets indicate the state of traits in the original text; abbreviations in square brackets: UFC: unique forward change; HFC: homoplasious forward change; HR: homoplasious reversal, forward changes are from state 0 to 1 to 2 and reversal changes follow the opposite order (eg. state 2 to state 1); group numbers I to VII are from higher to lower level of taxonomic categories
1. Ch. 61. Suture separating mesoventrite from mesopleuron ("mesanepisternum" in original text) absent or represented at most by a solid suture in posterior region $1 / 3$ (1) [UFC].

2. Ch. 60. Suture separating mesoventrite from metaventrite absent laterally or entirely missing (1) (HFC);

3. Ch. 78. External protibial edge without spines (1) [HFC];

4. Ch. 80. Tarsi three-segmented (2) [UFC].

5. Ch. 51. Pronotum without lateral carina (1) $[\mathrm{HFC}]$;

6. Ch. 55. Pronoto-prosternal membranous connection completely absent (2) [HFC];

7. Ch. 56. Procoxal fissure closed, trochantin completely concealed in ventrolateral view (2) [UFC];

8. Ch. 57. Procoxae without keel (1) [HFC];

9. Ch. 58. Pronotal postcoxal process strongly reduced or absent (1) [HFC];

10. Ch. 69. Elytron without numerous rows of punctures (1) [HFC];

11. Ch. 82. Tarsal empodia without setae (2) [HFC].

12. Ch. 5. Foveae on mesoventrite present (1) [HFC].

13. Ch. 63. Mesopleural ridge ("sulcus") absent (2) [UFC].

14. Ch. 66. Metacoxae separated by more than 0.1 coxal width (1) [HFC];

15. Ch. 68. Elytron without epipleural keel (1) [HFC].

16. Ch. 6. Foveae on metaventrite absent (0) [HR];

17. Ch. 53. Pronotum without transverse antebasal impression (0) [HR];

18. Ch. 65. Suture separating mesepimeron from metaventrite absent (2) [HFC];

19. Ch. 71. Elytron with apex straight or evenly arcuate near lateral margin (0) [HR];

20. Ch. 81. Tarsal claw 1 (2) [HFC];

21. Ch. 84. Mesotrochanter long, with entire femoral base distinctly separated from coxal cavity (1) [HFC].
I. Omaliine group

II. Pselaphine lineage

III. Protopselaphinae + Pselaphinae

IV. Pselaphinae

V. Pselaphinae excluding Faronitae

VI. Pselaphitae, Clavigeritae

VII. Clavigeritae process of the elytra corresponding to the anterior concavity of the dorsal side of the mesothorax (Fig. 7e). We did not observe differences in these features between individuals with the variants I and II of wing reduction. It is very likely that this is due to an advanced stage of flight loss in both cases, when even the less reduced type of wings is non-functional and occupies only a small space below the elytra. The set of elytral locking mechanisms is a complex suite of apomorphies not described in any other groups of beetles so far. However, at present, data for closely related taxa are insufficient for a systematic evaluation.

Loss of flight is a common phenomenon in Coleoptera (Smith 1964). Flightless beetles can show only a simple degeneration of tissue of indirect fight muscles like in Amphizoidae (Beutel 1988), or various muscular reductions (Larsén 1966) and skeletal simplifications, including a complete loss of wings and different associated structures (Luo et al. 2018, 2019). Only few anatomical studies on the thorax of flightless beetles are available. However, it appears that the pattern of muscle losses varies only slightly, with the loss of large indirect flight muscles followed by the reduction of the smaller direct muscles in more advanced forms (Larsén 1966, Luo et al. 2018, 2019). Remarkably, the whirligig beetle Orectochilus villosus O.F. Müller shows a high degree of muscle reduction in the metathorax but has retained its ability to fly (Liu et al. 2018).
Wings may be polymorphic within populations of the same species, with the occurrence of macropterous and brachypterous individuals (e.g., Smith 1964; in Pselaphinae see e.g., Nomura 1991). Distinct skeletal simplifications observed in cave-dwelling Carabidae and Leiodidae (e.g., Peck 1973: Fig. 7) indicate irreversibility of the wing reduction (e.g., Luo et al. 2018, 2019). Unlike in the flightless and eyeless Sinaphaenops wangorum Ueno \& Ran, 1998 (Carabidae) and Troglocharinus ferreri (Leiodidae), or in scydmaenines of the tribe Mastigini (Jałoszyński 2018), the metanotum of C. testaceus, a crucial element of the flight apparatus, shows only a minor degree of reduction. It is distinctly shortened in relation to the mesonotum and compared with the metanota of winged pselaphines belonging to other supertribes (Fig. 2e vs. Fig. S2a-f) but has still retained most of its structural elements. Other skeletal structures such as the pterothoracic phragmata, metanotal wing processes, and pleural muscle discs are distinctly or completely reduced. Three-dimensional reconstructions of $C$. testaceus revealed a distinctly reduced metathoracic muscle system. According to Hlaváč (2005), anophthalmous species of Clavigeritae of the northern temperate regions are always unable to fly and never actively leave their host's colonies, in contrast to tropical relatives with functional compound eyes and wings. Consequently, the farreaching reduction of flight muscles and some skeletal elements of the flight apparatus in C. testaceus is not surprising. 


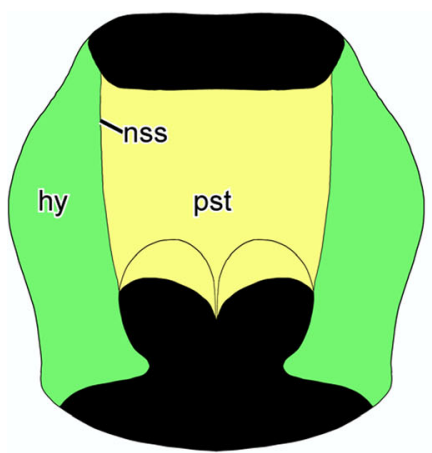

a

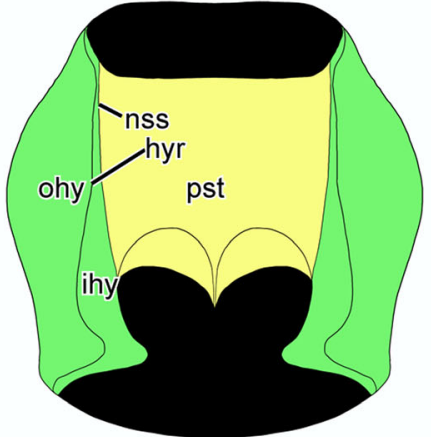

b

Fig. 10 Hypothetical steps in the evolution of the prothorax in Claviger, ventral view. a groundplan (prosternum separated from undivided hypomera by complete notosternal sutures); b hypomera subdivided by hypomeral ridges (inner portion of hypomeron thickened, reinforces adcoxal region); c prosternum fused with hypomera (notosternal sutures

However, that some flight-related structures remain relatively well-developed, like the metanotum, and that vestigial wings still occur, indicates that the mechanism of reduction is genetically not completely fixed yet and may therefore be the result of a relative young evolutionary process.

\section{Myrmecophilous habits}

Due to their greatly reduced mouthparts, $C$. testaceus and related species rely on feeding by host ant workers (Akre and Hill 1973; Hermann 1982). Profound myrmecophilous adaptations related to the mouthparts and other cephalic structures of Claviger were a subject of a separate study (Jałoszyński et al., 2020).

Despite of lacking defensive glands, myrmecophilous pselaphine species can permanently live and reproduce in ant colonies (Parker 2016a). One modification facilitating myrmecophilous habits of $C$. testaceus and related species is size reduction. Small or very small body size (usually $1-3 \mathrm{~mm}$ in Pselaphinae) can play an important role in association with ant hosts (Parker 2016a), facilitating transportation of eyeless and flightless beetles by workers (Hermann 1982) and making it easier to move inside the ant nest tunnels.

Another character complex is an unusually compact and robust thorax and abdomen. In $C$. testaceus this adaptation includes an internalized protrochantinus and partially internalized procoxa, the high degree of fusion of the pterothoracic segments, and the lack of sutures separating the lateral pleural sclerites from the ventrites. The lack of thoracic sutures and the highly compacted segments make the beetles less vulnerable to attacks by ant workers using their mandibles. This also applies to the short legs with their thickened cuticle, with flattened tibiae, and shortened tarsi, considered as a common feature in myrmecophilous beetles, likely reducing the risk of losing limbs in interaction with host ants (Parker 2016a). Additionally, the highly complex elytral interlocking

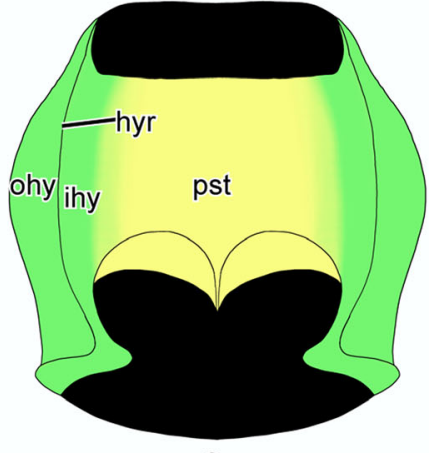

C

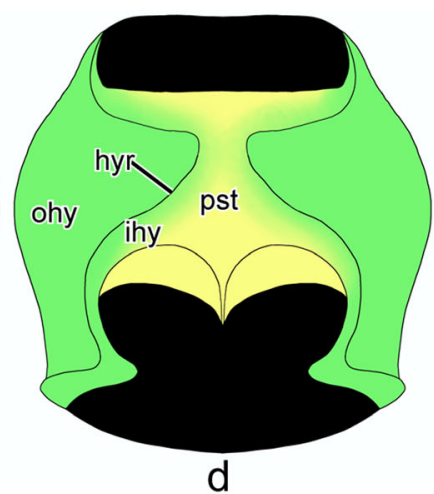

d obliterated); d Claviger (hypomeral ridges strongly bent mesad, prosternum narrowed medially). Abbreviations: hy, hypomeron; hyr, hypomeral ridge; ihy, inner region of hypomeron; nss, notosternal suture; ohy, outer region of hypomeron; pst, prosternum

mechanism enhances the protection of the less-sclerotized dorsal parts of the pterothorax and anterior abdomen. Unlike in many other small beetles (e.g., Scydmaeninae), the elytra of C. testaceus are not easy to separate from the thorax during dissection. In beetles with strongly convex elytra, pressure applied from above often results in separating the elytra and exposing the delicate dorsal pterothorax and anterior abdomen. The dorsally flattened elytra of $C$. testaceus likely reduce this risk. Not only the interlocking mechanisms are relevant in this context, but also the ventrally deflexed, broad epipleura, which effectively clasp the sides of the thorax. This ensures that the elytra stay in place when an ant grasps this body region, and vulnerable structures beneath them remain well protected. The same function can be ascribed to the heavily sclerotized and fused postelytral abdominal segments, where the attention of host ants is directed by trichomes, from which workers lick appeasement secretions (Hill et al. 1976; Cammaerts 1974, 1977).

Foveae on the surface, which are common in Pselaphinae (e.g., Chandler 2001), are almost entirely absent in C. testaceus (except for a pair of somewhat reduced ones on the anteromedian region of the mesoventrite) and also occasionally missing in other pselaphine subgroups (e.g., Parker and Maruyama 2013). The abdomen of species of Clavigeritae is certainly not as flexible as, for instance, in ant-associated Aleocharinae (Parker 2016a: Fig. 4).

We assume that the increased rigidity of the abdomen of Clavigeritae (Jeannel 1950: Fig. 23) provides improved protection against ants. However, it is likely that this is linked with a drastically reduced movability of this unusually short and broad tagma. It was pointed out by Blum (1979) that shortened elytra, correlated with a highly movable abdomen, are a characteristic feature of rove beetles, linked with the presence of diagonally crossed abdominal muscles. He found this condition in different groups of Staphylinidae, with the notable exception of 


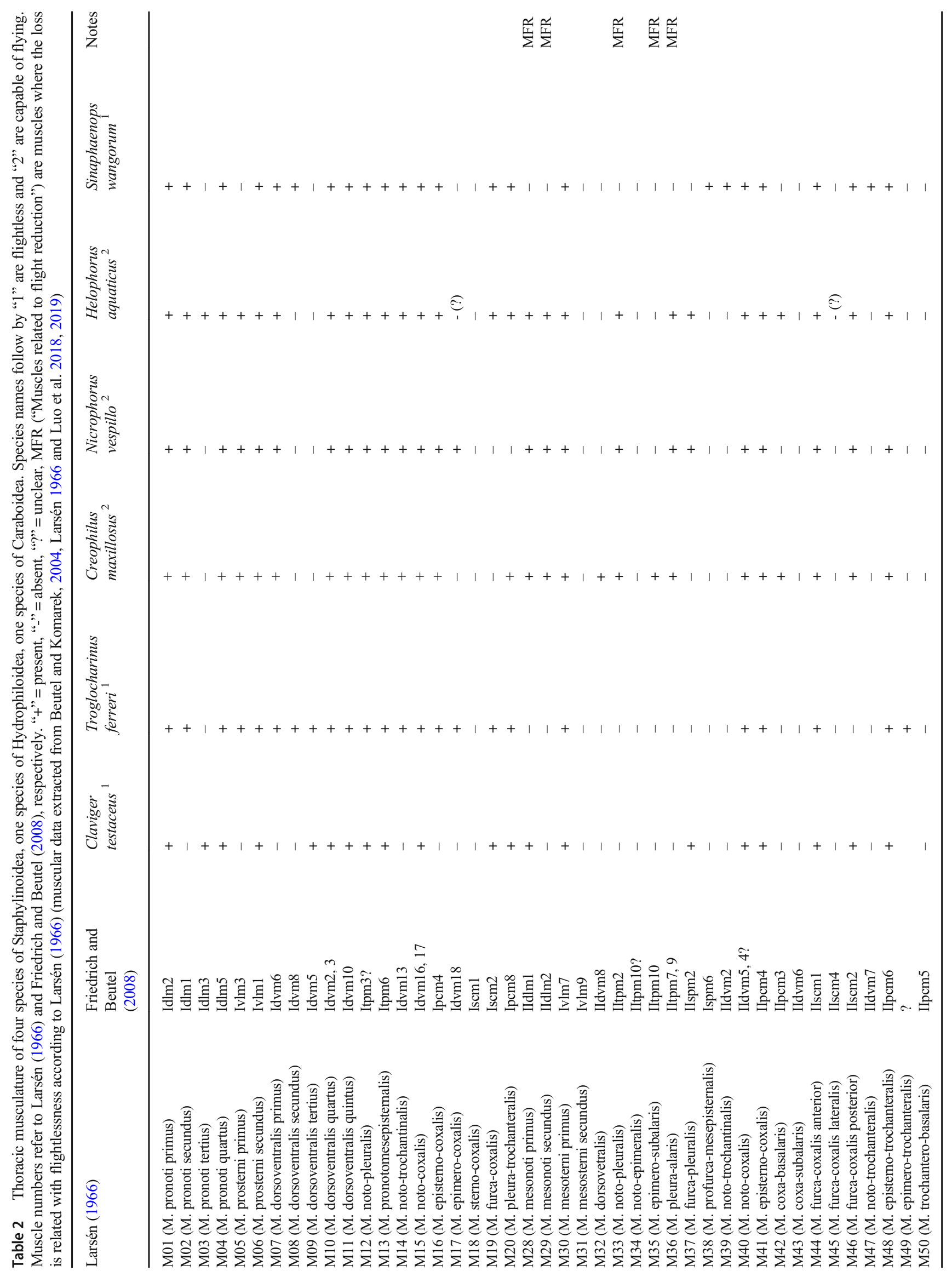




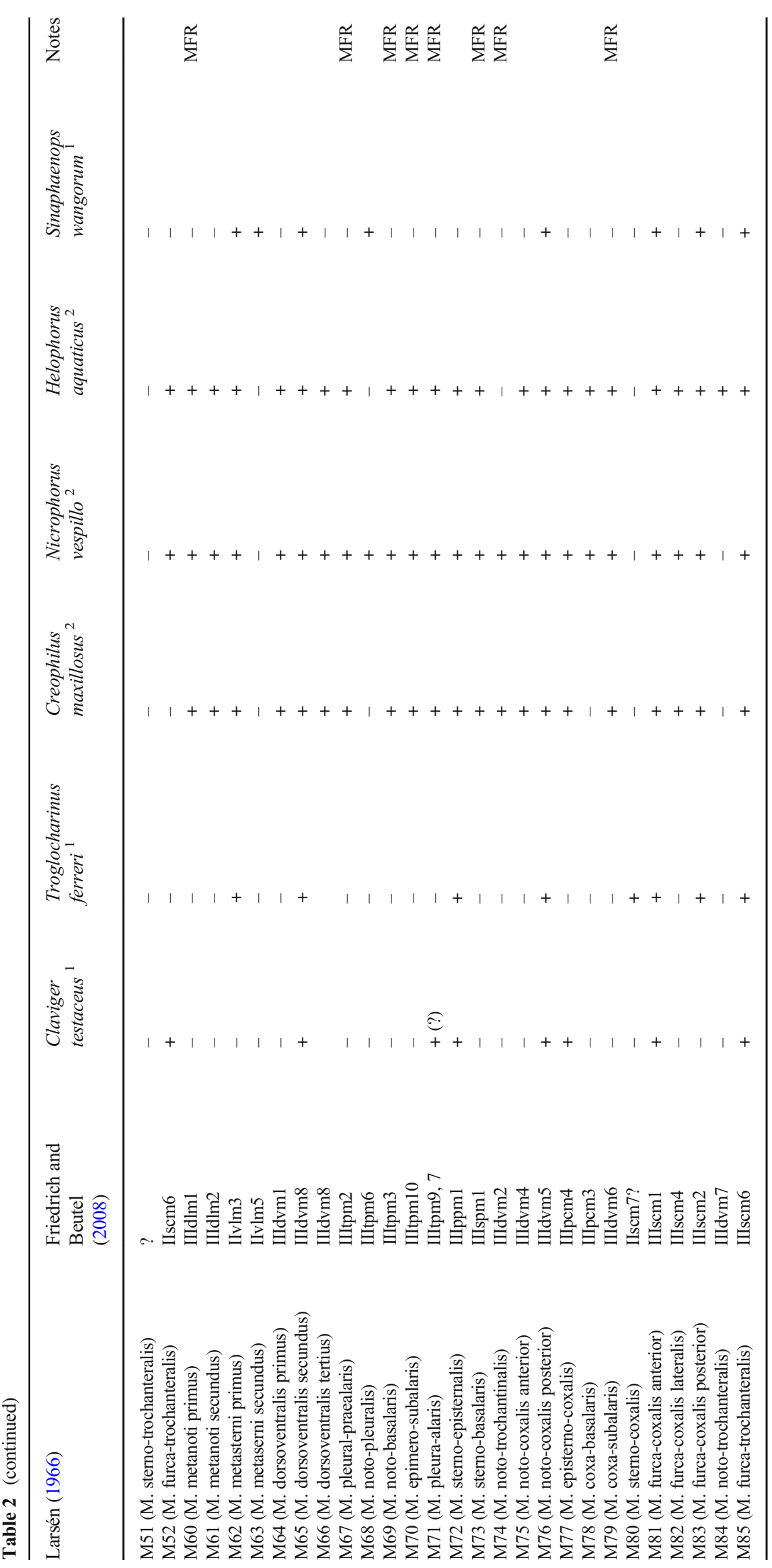


Omaliinae, a group with exceptionally long elytra compared with other subfamilies. His sampling did not include members of Pselaphinae, by that time still considered as a separate family. However, even though we did not examine the posterior abdominal segments, our findings suggest that the movability is reduced to a minimum in Claviger, and very likely also in related groups. The parallel-sided longitudinal muscles of the proximal abdomen probably allow for limited vertical movements, but torsions of the tagma can be excluded with certainty. Functional consequences outlined by Blum (1979) are the lacking ability to fold and clean the wings using the abdomen. However, this is irrelevant in the case of the flightless Claviger. Considering the systematic position of Pselaphinae, it is likely that the high abdominal movability and diagonally crossed muscles were secondarily reduced within the subfamily. It is conceivable this was not the case in Faronitae with a comparatively long abdomen or also in Protopselaphus, but anatomical data are completely lacking for these groups. The abdominal muscles remain also unstudied in other staphylinid subfamilies characterized by short or long abdomens, with a limited ability of lateral and dorso-ventral movements (e.g., Micropeplinae or Osoriinae).

\section{Conclusions}

In summary, a remarkable degree of morphological modification of the thorax (and other body parts) of Clavigeritae leads to an optimization of intimate associations with ants, keeping the ecological coexistence stable and sustainable. Parts of the morphological syndrome making specialized staphylinid beetles well able to cope with the challenging life in ant colonies evolved in several steps. This occurred long before myrmecophilous habits were established in subordinate groups within the Omaliine lineage.

Supplementary Information The online version contains supplementary material available at https://doi.org/10.1007/s13127-021-00484-1.

Acknowledgments We are very grateful to PD. Dr. Hans Pohl (FSU Jena) for his assistance with the preparation of SEM samples. The first author wants to express his thanks to CSC (No. 201708440281). The second author is indebted to Miłosz Mazur (University of Opole, Poland) for organizing a field trip on which $C$. testaceus was collected, and Dr. Rafał Ruta (University of Wrocław, Poland) for his help with collecting the beetles. We are also grateful for helpful comments made by an anonymous reviewer and Prof. Dr. Michael Ohl (Naturkundemuseum Berlin), and to Dr. Margaret Thayer (Field Museum, Chicago) and Prof. Dr. Alexey Polilov (Moscow State University) for providing literature.

Funding Open Access funding enabled and organized by Projekt DEAL. CSC (No. 201708440281).
Data availability The datasets generated during and/or analyzed during the current study are available from the corresponding author on reasonable request.

\section{Compliance with ethical standards}

Conflict of interest The authors declare that they have no conflict of interest.

Open Access This article is licensed under a Creative Commons Attribution 4.0 International License, which permits use, sharing, adaptation, distribution and reproduction in any medium or format, as long as you give appropriate credit to the original author(s) and the source, provide a link to the Creative Commons licence, and indicate if changes were made. The images or other third party material in this article are included in the article's Creative Commons licence, unless indicated otherwise in a credit line to the material. If material is not included in the article's Creative Commons licence and your intended use is not permitted by statutory regulation or exceeds the permitted use, you will need to obtain permission directly from the copyright holder. To view a copy of this licence, visit http://creativecommons.org/licenses/by/4.0/.

\section{References}

Akre, R. D., \& Hill, W. B. (1973). Behavior of Adranes taylori, a myrmecophilous beetle associated with Lasius sitkaensis in the Pacific northwest (Coleoptera: Pselaphidae; Hymenoptera: Formicidae). Journal of the Kansas Entomological Society, 46, 526-536.

Baehr, M. (1975). Skelett und Muskulatur des Thorax von Priacma serrata Leconte (Coleoptera, Cupedidae). Zeitschrift für Morphologie der Tiere, 81(1), 55-101.

Beutel, R. G. (1988). Studies of the metathorax of the trout-stream beetle, Amphizoa lecontei Matthews (Coleoptera: Amphizoidae): Contribution towards clarification of the systematic position of Amphizoidae. International Journal of Insect Morphology and Embryology, 17(1), 63-81.

Beutel, R. G., Friedrich, F., Ge, S. Q., \& Yang, X. K. (2014). Insect morphology and phylogeny: A textbook for students of entomology. Berlin: De Gruyter.

Beutel, R. G., \& Haas, F. (2000). Phylogenetic relationships of the suborders of Coleoptera (Insecta). Cladistics, 16(1), 103-141.

Beutel, R. G., \& Komarek, A. (2004). Comparative study of thoracic structures of adults of Hydrophiloidea and Histeroidea with phylogenetic implications (Coleoptera, Polyphaga). Organisms, Diversity and Evolution, 4(1-2), 1-34.

Blum, P. (1979). Zur Phylogenie und ökologischen Bedeutung der Elytrenreduktion und Abdomenbeweglichkeit der Staphylinidae (Coleoptera). Vergleichend-und funktionsmorphologische Untersuchungen. Zoologische Jahrbücher für Anatomie, 102, $533-582$

Cammaerts, R. (1973). Etude histologique du système glandulaire tégumentaire du Coléoptère myrmécophile Claviger testaceus Preyssler (Pselaphidae). Proceedings of the 7th international congress of IUSSI, London: 56-61.

Cammaerts, R. (1974). Le système glandulaire tégumentaire du coléoptère myrmécophile Claviger testaceus Herbst, 1792 (Pselaphidae). Zeitschrift für Morphologie und Ökologie der Tiere, 77, 187-219.

Cammaerts, R. (1977). Secretions of a beetle inducing regurgitation in its host ant. Proceedings of the 8th International Congress of the International Union for the Study of Social Insects, Wageningen, 295. 
Cammaerts, R. (1992). Stimuli inducing the regurgitation of the workers of Lasius flavus (Formicidae) upon the myrmecophilous beetle Claviger testaceus (Pselaphidae). Behavioural Processes, 28, 81-95.

Cammaerts, R. (1995). Regurgitation behavior of the Lasius flavus worker (Formicidae) towards the myrmecophilous beetle Claviger testaceus (Pselaphidae) and other recipients. Behavioural Processes, 34, 241-264.

Cammaerts, R. (1996). Factors affecting the regurgitation behaviour of the ant Lasius flavus (Formicidae) to the nest beetle Claviger testaceus (Pselaphidae). Behavioural Processes, 38, 297-312.

Chandler, D. S. (2001). Biology, morphology and systematics of the antlike litter beetle genera of Australia (Coleoptera: Staphylinidae: Pselaphinae).\&nbsp;Memoirs on entomology, international volume 15. Gainesville: Florida, Associated Publishers.

Donisthorpe, H. (1927). The guests of British ants: Their habits and life histories. London: George Routledge \& Sons.

Fikáček, M., Beutel, R. G., Cai, C., Lawrence, J. F., Newton, A. F., Solodovnikov, A, Yamamoto, S. (2020). Reliable placement of beetle fossils via phylogenetic analyses-Triassic Leehermania as a case study (Staphylinidae or Myxophaga?). Systematic Entomology, 45(1), 175-187.

Friedrich, F., \& Beutel, R. G. (2008). The thorax of Zorotypus (Hexapoda, Zoraptera) and a new nomenclature for the musculature of Neoptera. Arthropod Structure \& Development, 37, 29-54.

Friedrich, F., Farrell, B. D., \& Beutel, R. G. (2009). The thoracic morphology of Archostemata and the relationships of the extant suborders of Coleoptera (Hexapoda). Cladistics, 25, 1-37.

Gorb, S. N. (1998). Frictional surfaces of the elytra-to-body arresting mechanism in tenebrionid beetles (Coleoptera: Tenebrionidae): Design of co-opted fields of microtrichia and cuticle ultrastructure. International Journal of Insect Morphology and Embryology, 27(3), 205-225.

Hermann, H. R. (1982). Social insects volume 3. New York, San Francisco, London: Academic press.

Hill, W. B., Akre, R. D., \& Huber, J. D. (1976). Structure of some epidermal glands in the myrmecophilous beetle Adranes taylori (Coleoptera: Pselaphidae). Journal of the Kansas Entomological Society, 49, 367-384.

Hlaváć, P. (2005). Thysdariella, a new genus of the myrmecophilous supertribe Clavigeritae (Coleoptera: Staphylinidae, Pselaphinae) from Madagascar. The Coleopterists Bulletin, 59(3), 304-309.

Jałoszyński, P. (2018). World genera of Mastigitae: Review of morphological structures and new ecological data (Coleoptera: Staphylinidae: Scydmaeninae). Zootaxa, 4453(1), 1-119.

Jałoszyński, P. (2020). Aenigmaphes gen. n., a new glandulariine genus of the Australian region (Coleoptera: Staphylinidae: Scydmaeninae). Zootaxa, 4731(3), 439-446.

Jałoszyński, P., Luo, X.-Z., \& Beutel, R. G. (2020). Profound head modifications in Claviger testaceus (Pselaphinae, Staphylinidae, Coleoptera) facilitate integration into communities of ants. Journal of Morphology, 281(9), 1072-1085.

Jeannel, R. (1950). Coléoptéres psélaphides. Faune de France, 53, 1421.

Klima, J. (1983). Die Gesperre der Käfer-Elytren und deren phylogenetische Bedeutung. Berichte des naturwissenschaftlichen medizinischen Vereins in Innsbruck, 70, 155-165.

Larsén, O. (1966). On the morphology and function of locomotor organs of the Gyrinidae and other Coleoptera. Opuscula Entomologica Supplementum, 30, 1-241.

Lawrence, J. F., \& Ślipiński, S. A. (2013). Australian Beetles (Vol. 1). Collingwood: CSIRO Publishing.

Liu, S. P., Wipfler, B., \& Beutel, R. G. (2018). The unique locomotor apparatus of whirligig beetles of the tribe Orectochilini (Gyrinidae, Coleoptera). Journal of Zoological Systematics and Evolutionary Research, 56(2), 196-208.
Luo, X. Z., Antunes-Carvalho, C., Ribera, I., \& Beutel, R. G. (2019). The thoracic morphology of the troglobiontic cholevine species Troglocharinus ferreri (Coleoptera, Leiodidae). Arthropod Structure \& Development, 53, 100900.

Luo, X. Z., Wipfler, B., Ribera, I., Liang, H. B., Tian, M. Y., Ge, S. Q., \& Beutel, R. G. (2018). The thoracic morphology of cave-dwelling and free-living ground beetles from China (Coleoptera, Carabidae, Trechinae). Arthropod Structure \& Development, 47, 662-674.

Newton, A. F., \& Thayer, M. K. (1995). Protopselaphinae new subfamily for Protopselaphus new genus from Malaysia, with a phylogenetic analysis and review of the Omaliine Group of Staphylinidae including Pselaphidae (Coleoptera). In J. Pakaluk \& A. Ślipiński (Eds.), Biology, phylogeny, and classification of Coleoptera: Papers celebrating the 80th birthday of Roy a. Crowson (pp. 221-320). Warszawa: Muzeum i Instytut Zoologii PAN.

Nomura, S. (1991). Systematic study on the genus Batrisoplisus and its allied genera from Japan (Coleoptera, Pselaphidae). Esakia, 30, 1462.

Parker, J. (2016a). Myrmecophily in beetles (Coleoptera): Evolutionary patterns and biological mechanisms. Myrmecological News, 22, 65108.

Parker, J. (2016b). Emergence of a superradiation: pselaphine rove beetles in mid-Cretaceous amber from Myanmar and their evolutionary implications. Systematic Entomology, 41, 541-566.

Parker, J., \& Grimaldi, D. A. (2014). Specialized myrmecophily at the ecological dawn of modern ants. Current Biology, 24, 2428-2434.

Parker, J., \& Maruyama, M. (2013). Jubogaster towai, a new Neotropical genus and species of Trogastrini (Coleoptera: Staphylinidae: Pselaphinae) exhibiting myrmecophily and extreme body enlargement. Zootaxa, 3630, 369-378.

Peck, S. B. (1973). A systematic revision and the evolutionary biology of the Ptomaphagus (Adelops) beetles of North America (Coleoptera; Leiodidae; Catopinae), with emphasis on cave-inhabiting species. Bulletin of the Museum of Comparative Zoology at Harvard College, 145, 29-162.

Pohl, H. (2010). A scanning electron microscopy specimen holder for viewing different angles of a single specimen. Microscopy Research and Technique, 73, 1073-1076.

Rivera, J., Hosseini, M. S., Restrepo, D., Murata, S., Vasile, D., Parkinson, D. Y., Barnard, H. S., Arakaki, A., Zavattieri, P., \& Kisailus, D. (2020). Toughening mechanisms of the elytra of the diabolical ironclad beetle. Nature, 586(7830), 543-548.

Schneeberg, K., Bauernfeind, R., \& Pohl, H. (2017). Comparison of cleaning methods for delicate insect specimens for scanning electron microscopy. Microscopy Research and Technique, 80, 1199-1204.

Smith, D. S. (1964). The structure and development of flightless Coleoptera: A light and electron microscopic study of the wings, thoracic exoskeleton and rudimentary flight musculature. Journal of Morphology, 114(1), 107-183.

Thayer, M. K. (2016). Staphylinidae Latreille, 1802. In: Beutel, R.G., Leschen, R.A.B. (Volume eds.), Coleoptera, beetles. Volume 1: Morphology and systematics (Archostemata, Adephaga, Myxophaga, Polyphaga partim). In Handbook of Zoology (pp. 394-442). Walter de Gruyter Berlin.

Weide, D., \& Betz, O. (2009). Head morphology of selected Staphylinoidea (Coleoptera: Staphyliniformia) with an evaluation of possible groundplan features in Staphylinidae. Journal of Morphology, 270, 1503-1523.

Weide, D., Thayer, M. K., \& Betz, O. (2014). Comparative morphology of the tentorium and hypopharyngeal-premental sclerites in sporophagous and non-sporophagous adult Aleocharinae (Coleoptera: Staphylinidae). Acta Zoologica, 95, 84-110.

Weide, D., Thayer, M. K., Newton, A. F., \& Betz, O. (2010). Comparative morphology of the head of selected sporophagous and non sporophagous aleocharinae (Coleoptera: Staphylinidae): 
Musculature and hypopharynx prementum complex. Journal of Morphology, 271, 910-931.

Yavorskaya, M. I., Beutel, R. G., Farisenkov, S. E., \& Polilov, A. A. (2019). The locomotor apparatus of one of the smallest beetles-the thoracic skeletomuscular system of Nephanes titan (Coleoptera, Ptiliidae). Arthropod Structure \& Development, 48, 71-82.

Yin, Z. W., Kurbatov, S. A., Cuccodoro, G., \& Cai, C. Y. (2019). Cretobrachygluta gen. Nov., the first and oldest Brachyglutini in
mid-Cretaceous amber from Myanmar (Coleoptera: Staphylinidae: Pselaphinae). Acta Entomologica Musei Nationalis Pragae, 59(1), 101-106.

Publisher's note Springer Nature remains neutral with regard to jurisdictional claims in published maps and institutional affiliations. 